\title{
LA FORMACION DE UN CARTEL \\ EN EL PRIMER TERCIO DEL SIGLO XX: \\ LA INDUSTRIA DEL CEMENTO \\ PORTLAND *
}

\author{
A. GOMEZ MENDOZA \\ Universidad Complutense
}

La industria del cemento artificial portland constituye un caso típico de oligopolio en todos los países en los que está implantada. Se trata, quizá, del ejemplo más socorrido que encuentran los autores de tratados de economía. Por su propia naturaleza -canteras, inversión de capital fijo, costes variables modestos-, este sector está compuesto por un corto número de fabricantes.

No escapó la industria española a esta norma, brindándonos a los historiadores económicos la posibilidad de contar con un ejemplo temprano de oligopolio. La historiografía ha destacado el acentuado carácter oligopolista de buena parte de la industria española en el primer tercio del siglo xx. El proceso de restricción de la competencia se habría acentuado durante la dictadura de Primo de Rivera. Sin embargo, a pesar de las múltiples referencias historiográficas a la oligopolización industrial, nuestros conocimientos sobre el funcionamiento efectivo de esos oligopolios son escuetos.

El objetivo de este artículo es doble. Por un lado, se muestra que los orígenes del oligopolio del cemento portland se remontan al nacimiento del sector y no a los años de la Dictadura. Su razón de ser apunta a las características del producto y a la existencia de barreras a la entrada y no a la política económica de la década de 1920 (secciones 1 y 2). A continuación estudio las transformaciones del cártel por efecto de la Gran Guerra y de la crisis postbélica. A raíz de estos acontecimientos, la industria atravesó una fase de acentuación de la competencia dentro de una estructura oligopolista, fase que se prolongó hasta 1926 (secciones 3 y 4). La política de intervención estrenada en 1926 llevó al establecimiento de nuevas fábricas, muchas de ellas de escasa entidad, lo que agravó los efectos de la recesión iniciada en 1930 (sección 5).

* No habría podido llevar a término esta investigación de no haber contado con la asistencia de las entidades Compañía General de Asfaltos y Portland Asland, Cementos Portland y Cementos Uniland, que me permitieron acceder a sus archivos. Quiero agradecer a José Luis García Delgado y a los asistentes al II Seminario de Historia Cuantitativa los comentarios que hicieron a un primer borrador de este artículo. Como en otras ocasiones, también me he beneficiado de los consejos de Patrick O'Brien. Por último, no puedo olvidar al St. Antony's College (Oxford), que, al concederme su Deakin Fellowship, me proporcionó unas semanas de tranquilidad para la redacción de este artículo. 
Por otro lado, mi objetivo es analizar la toma de decisiones en el seno del cártel y sus efectos sobre la política de precios, reparto del mercado interior y fusiones entre empresas. Todos estos aspectos son tratados con mayor o menor detalle en todas las secciones, ofreciéndose una valoración final en las conclusiones. He intentado mostrar, asimismo, que la actuación del cártel español del portland en el primer tercio del siglo xx coincide de forma casi perfecta con el comportamiento teórico de un oligopolista (sección 6).

\section{LOS ORIGENES DE LA INDUSTRIA DEL CEMENTO PORTLAND EN ESPAÑA}

El cemento portland se obtiene mediante la calcinación, en las proporciones adecuadas, de una mezcla de calizas y margas arcillosas, previamente molidas. Por su color recuerda a la piedra de Portland, razón por la cual se le conoce habitualmente por ese nombre. La patente de fabricación fue registrada en 1824 por J. Aspdin, quien había perfeccionado el método seguido en 1757 por Smeaton, y años más tarde por el químico francés Vicat ${ }^{1}$. Para su fabricación pueden seguirse dos métodos. En la "vía húmeda» se mezclan las materias primas en la cantidad correcta por medio de agua. Fue el proceso habitual en el sigla xIx. Tiene dos inconvenientes: su duración y la posibilidad de que la mezcla obtenida no sea adecuada.

Por su lado, la «vía seca» consiste en secar perfectamente los distintos materiales que son molidos hasta formar un polvo fino («harina») con la que se obtiene una mezcla homogénea. Presenta como inconveniente el consumo en combustible necesario para secar perfectamente las materias primas y los gastos de primer establecimiento de los hornos rotatorios empleados. La adopción de estos hornos a comienzos del siglo xx, en Alemania y los Estados Unidos, transformó de forma radical a la industria cementera. En Inglaterra, por el contrario, persistió el procedimiento húmedo, que había alcanzado un desarrollo notable ${ }^{2}$.

La primera fábrica española de portland fue establecida en 1899 por la sociedad Tudela Veguin en las cercanías de Oviedo. Las bases de la industria del cemento artificial habían sido sentadas ya en 1905 con el establecimiento de algunas de las principales fábricas existentes en vísperas de la guerra civil: Cementos Rezola (1901), la Compañía General de Asfaltos y Portland Asland (1904) y Cementos Portland (1905). Con esas cuatro fábricas,

Davis (1909), p. 9.

2 Ibidem, pp. 39, 41-42, 48 y 53. 
la capacidad productiva se elevó a casi dos millares de toneladas diarias ${ }^{3}$. El procedimiento técnico más frecuente en España fue la «vía seca», pues el 60 por 100 de los hornos existentes en 1935 lo utilizaban.

Son varias las explicaciones que pueden adelantarse para la implantación del portland en los albores del siglo xx. La fecha de establecimiento de la primera fábrica - 1899 - puede hacer pensar en un posible vínculo con el desastre colonial. Tanto la repatriación de capitales como la búsqueda de nuevas oportunidades de inversión en sectores otros que la industria de bienes de consumo, la más afectada por la pérdida de las últimas colonias, desempeñaron, sin duda, un papel importante. Habida cuenta de que se trataba de un sector nuevo, es necesario destacar el buen criterio de hombres de negocios como Güell, Huici o Rezola, que supieron sacar partido a la abundancia, baratura y calidad de las materias primas en España.

Las construcciones residenciales, caracterizadas por una marcada apatía en los primeros años del siglo, junto con la resistencia inicial por parte de los constructores a sustituir el cemento natural por el artificial en las obras, no fueron factores favorables al desarrollo de esta industria. Sí lo fue, en cambio, el auge dado a las obras de infraestructura, en particular a la construcción de pantanos, modernización y ampliación de los puertos ${ }^{4}$.

Las primeras fábricas compartían una serie de rasgos comunes. Todas ellas, salvo la diminuta establecida en las proximidades de Zaragoza, fueron ubicadas a corta distancia del litoral. Ya que las materias primas abundan en cualquier paraje, esa localización respondía a dos factores: la disponibilidad de carbón a buen precio y las condiciones del mercado. En la fabricación del portland se consumía entre $1 / 4$ y $1 / 2$ tonelada de hulla por cada tonelada de clínquer, proporción que dependía de la tecnología utilizada. Aunque la calidad de la hulla afectaba a los costes medios de fabricación, por lo general, las fábricas españolas no fueron excesivamente exigentes. Casi todas ellas consumieron preferentemente hullas nacionales e incluso de ínfima calidad, como ocurría en la fábrica primitiva de Asland, que se abastecía con carbón en polvo de Figols, que se acostumbraba tradicionalmente a verter en el río por no tener aplicación en la industria textil local ${ }^{5}$. La mayor baratura del carbón en puertos de mar, unido al hecho de que el cemento es un producto de escaso valor, muy sensible al precio del transporte, son, por consiguiente, dos factores para explicar la elección de un emplazamiento cercano al litoral.

${ }^{3}$ Palomar (1940).

4 Gómez Mendoza (1986), gráfico 1, p. 62. También, el capítulo «La Industria de la Construcción», en mi libro en preparación El Producto Industrial en España, 1850-1935.

5 Asland, Actas de las Reuniones del Consejo de Administración, sesión 17-1-1911. El combustible más apropiado para los hornos rotatorios era la hulla bituminosa, con un bajo contenido en cenizas (menos de un 10 por 100), una humedad de un 5 por 100 y un 1,5 por 100 de azufre. Véase Davis (1909), p. 140. 
Cabe destacar, en segundo lugar, el marcado carácter familiar de algunas de las principales empresas del sector, carácter que se ha perpetuado hasta fechas recientes. La sociedad Asland fue constituida en 1901 por don Eusebio Güell, destacando entre sus consejeros varios miembros de esa familia y también de los Bertrán, con quienes estaban emparentados ${ }^{6}$. Esta característica se repite en otras sociedades como Cementos y Cales Freixa, Cementos Landfort de J. Fradera o Cementos Rezola?.

La tercera característica a destacar es la elevada dependencia tecnológica del exterior. Los primeros fabricantes adquirieron patentes en el extranjero, costearon la estancia en España a ingenieros y químicos extranjeros que supervisaron la instalación de las fábricas y el encendido de los hornos y, finalmente, enviaron a Alemania, Dinamarca o Estados Unidos a sus propios ingenieros para que realizaran prácticas en esos países. Aprovechando la circunstancia de ser un sector totalmente nuevo en España, se importó tecnología punta que incluso fue objeto de alguna modificación ${ }^{8}$. Asland adquirió patentes americanas de la casa Allis Chalmer, mientras que Portland se decantó por la tecnología europea de las casas alemanas, danesas o suizas, como Giesecke y Smidth, entre otras?.

\section{LA UNION DE FABRICANTES DE CEMENTO PORTLAND DE 1906}

Una de las virtudes del cemento es que las diferencias de calidad entre las distintas marcas son mínimas, debiéndose éstas a los grados de finura introducidos en la molturación final, a la presentación del producto acabado y a su comercialización ${ }^{10}$. El cemento portland constituye un producto altamente homogéneo, por lo que se puede considerar que una marca era perfectamente sustituible por otra. Así, pues, desde el punto de vista de sus características físicas, la elasticidad de sustitución del cemento es prácticamente

- En el acta de constitución figuraban otros apellidos no menos relevantes: Arnús y Fortuny, Miralles del Imperial, Ferrer Vidal y Massó Casanas, entre otros.

${ }^{7}$ El carácter familiar de estas sociedades era especialmente llamativo en el caso de Cementos y Cales Freixa. Los únicos socios constituyentes de esta sociedad fueron María Rosario, Dolores, Concepción y Joaquina Freixa y Peyra, aunque ninguna de ellas figuraba en el Consejo.

- Según Palomar, la adopción definitiva del horno rotatorio se debió al ingeniero Alfonso de Navarro, que en 1890 lo instaló en la fábrica Atlas, en los Estados Unidos. Véase Palomar (1941-42), p. 22.

Asland, Actas, ss. 30-12-1902, 30-12-1903, 21-3-1904; Portland, Actas, ss. 1-7-1903, 20-9-1903 y 10-1-1904.

${ }_{10}$ Las marcas más frecuentes eran «Asland», de la sociedad del mismo nombre; «Cangrejo» y «Diamante», de Cementos Portland; «Sansón», de la Auxiliar, y «Landfort», de la casa Fradera. 
infinita. No lo es, sin embargo, cuando se introducen consideraciones geográficas, por tratarse de una mercancía voluminosa de bajo valor, muy sensible al recargo del transporte. De ahí que el cemento viajara a cortas distancias, hecho que es cierto aún hoy en día. Por ejemplo, en los años 1960, 9 de cada 10 toneladas de cemento artificial vendidas en los Estados Unidos habían recorrido distancias inferiores a 160 millas ${ }^{11}$. Las consecuencias de este hecho son claras. En primer lugar, el concepto de mercado nacional, y por extensión el de precio medio nacional, carece de sentido, siendo más propio hacer referencia a una yuxtaposición de mercados regionales. La dispersión geográfica de las fábricas responde a un intento por minimizar los costes de distribución del producto acabado y de retorno de los envases vacíos. En segundo lugar, dicha fragmentación del mercado motiva que sólo las marcas de una localidad, suponiendo que la calidad sea comparable, sean perfectamente sustituibles entre sí a los ojos del consumidor.

Una segunda nota distintiva es el hecho de tratarse de una industria altamente intensiva en capital, lo que comporta la realización de apreciables economías de escala. Hacia finales de nuestro período se cifraba el desembolso inicial en 100 a 125 pesetas por cada tonelada de capacidad instalada, cantidad que se incrementaba en otras 40 a 25 pesetas, respectivamente, si la fábrica había de generar su propia energía ${ }^{12}$. Por esa razón, y porque, además, era aconsejable entrar en el sector a una escala de operaciones considerable, la disponibilidad de recursos financieros cuantiosos o, en su defecto, el acceso a fuentes de financiación barata constituían el principal obstáculo para las nuevas empresas. $\mathrm{Ni}$ la disponibilidad de materias primas, muy abundantes por todo el país, ni la tecnología, de fácil adquisición en el extranjero, salvo durante la Primera Guerra Mundial, constituyeron barreras de entrada insalvables ${ }^{13}$. Otra barrera de entrada fue el arancel, que durante todo el período fue efectivo al mantener las importaciones a unos niveles mínimos, salvo en 1929. En ese año la autoridad económica autorizó la entrada de 300.000 toneladas de portland (rebajadas posteriormente a 218.000 ) con vistas a prevenir posibles desabastecimientos al culminar su programa de obras públicas con el Plan Guadalhorce. Dicho volumen representó un 14 por 100 de las ventas efectuadas en 1929 , lo que fue extraordinatio si se tiene en cuenta que las importaciones medias del período $1922-1931$ ascendieron a un 2,2 por 100 del consumo interior ${ }^{14}$.

${ }^{11}$ U. S. Federal Trade Commission (1966).

12 De Miguel (1935), p. 152.

13 "... hasta que las circunstancias no impidan como hasta ahora proyectar nuevas fábricas con las dificultades insuperables de su gran precio de coste y casi imposibilidad de recepción de maquinaria.... (Asland, Actas, ss. 29-4-1918).

${ }_{14}$ Estos porcentajes están inflados por incluir cementos naturales y cales entre los cementos importados. Todos los datos proceden de De Miguel (1935), p. 156. 
En virtud de lo expuesto en los dos puntos anteriores, se entiende que la estructura de la industria cementera tuviera un marcado carácter oligopolista. En unos pocos casos varias marcas competían por acaparar las ventas en un determinado mercado. Lo más frecuente era el caso de un mercado regional reservado a la producción de un único fabricante - su «mercado natural»que actuaba como monopolista puro ${ }^{15}$. A la estructura oligopolista se unía, además, una elevada concentración industrial. Un indicador habitual para medir la concentración es el porcentaje de la producción total atribuida a las tres o cinco principales sociedades (incluidas sus filiales) ${ }^{16}$.

\section{CUADRO 1}

Concentración industrial en la industria del portland (Años seleccionados y porcentajes)

\begin{tabular}{|c|c|c|c|c|}
\hline & 1914 & 1918 & 1924 & 1930 \\
\hline «Concentración Industrial $» \ldots \ldots \ldots \ldots$ & 83 & 73 & 70 & 60 \\
\hline
\end{tabular}

FUENTES Y NOTAS: $« \mathrm{CI}_{\gg}=\sum_{i=1}^{5} O_{i} / O$, siendo $O$ la producción total de cemento portland y $O_{i}$ la producción de las cinco sociedades seleccionadas: Asland, Auxiliar de la Construcción, Fradera, Portland y Rezola. En 1914 se excluye Auxiliar y Fradera; en 1918 se excluye Auxiliar. Toda la información sobre producciones procede de las Estadisticas Mineras, años seleccionados.

A la vista de los porcentajes que aparecen en el cuadro 1 , se puede afirmar que la concentración industrial se mantuvo a lo largo de todo el período, aunque la tendencia fue decreciente. Sin embargo, como el número de fábricas aumentó desde 6 establecimientos en 1914 hasta casi 30 en 1930, la cuota media correspondiente a las demás fábricas disminuyó desde un 5,5 por 100 en el primer año hasta un mero 1,6 por 100 en el segundo, razón por la cual debe hablarse, en realidad, de un aumento relativo de la concentración. Se confirma, pues, que las cinco principales empresas cementeras controlaban una

${ }^{15} \mathrm{La}$ industria del cemento artificial constituye un ejemplo clásico del oligopolio en todos los libros de teoría económica. Las referencias bibliográficas son muy extensas, siendo posible destacar las siguientes obras: Loescher (1959); Meyzenc (1968); U. S. Federal Trade Commission (1966).

16 Scherer (1970), pp. 50-51. 
sustancial cuota del mercado interior. La exclusividad del suministro en los mercados «naturales» de cada una de ellas sugiere que los índices de concentración podían ser muy superiores dentro del radio de acción de cada fábrica.

Tras examinar las principales características de la industria cementera, voy a ocuparme del proceso que llevó a la constitución del primer pacto entre fabricantes.

En el período 1899-1914 se crearon un total de 8 fábricas de portland, entre ellas Asland, Portland, Rezola y Fradera, aunque esta última se dedicaba principalmente a la fabricación de cementos naturales. La producción conjunta de los establecimientos citados ascendía en 1914 a un 83 por 100 de la producción global española. Tan elevada concentración industrial había necesariamente de quedar plasmada en un sustancial control del mercado, robustecido por el hecho de que ninguna de ellas tenía capacidad para colocar su producción en el «mercado natural» de otra.

Transcurrido un año y medio después de que la fábrica de Asland, sita en el Clot del Moro, encendiera sus hornos, y apenas tres meses desde que entrara en funcionamiento la fábrica de Olazagutía, perteneciente a Portland, ambas sociedades entablaron conversaciones, a las que vino a sumarse Rezola, para repartirse el mercado interior. Con anterioridad a estas gestiones, Asland había intentado alcanzar un acuerdo particular con los Caminos de Hierro del Norte para establecer una tarifa especial ${ }^{17}$.

Bastaron, pues, unos pocos meses de «competencia alarmante... que hoy vienen sosteniendo [las tres fábricas] con perjuicio de las mismas» para que Asland, Portland y Rezola se avinieran a formar en 1906 la Unión de Fabricantes $^{18}$. El convenio fijaba precios en las distintas áreas comerciales, así como cuotas de ventas y un sistema de compensaciones entre los socios. Desgraciadamente, no conocemos el contenido de sus cláusulas ${ }^{19}$. Los objetivos eran evidentes: maximizar los beneficios conjuntos a través de una política común de precios que los acercara al precio monopolista. El acuerdo de principio sobre las virtudes de una asociación comercial no impidió, sin embargo, que fuera en extremo laborioso fijar los precios comunes y los controles para implementar el acuerdo ${ }^{20}$.

17 Fue la competencia del cemento extranjero quien obligó a Asland a intentar ese acercamiento. Al ser reforzada la protección con el nuevo arancel de 1906, Asland no volvió a ocuparse del asunto (Asland, Actas, ss. 26-2-1906).

${ }_{18}$ Asland, Actas, ss. 26-2-1906; Portland, Actas, ss. 11-4-1906.

19 El acuerdo regulaba también los precios en el mercado portugués, según se especifica en el Report on the Trade and Commerce of Spain for the year 1906, British Parl. Papers CXVI (1906), 137.

${ }^{20}$ Es decir, las tres sociedades se colocaron en una situación propia del oligopolista puro. Véase, al respecto, Stigler (1964). 
Portland proponía inspecciones de las fábricas asociadas con vistas a evaluar la producción, iniciativa a la que se oponía Asland ${ }^{21}$. El distinto poder negociador de cada sociedad, determinado en parte por su capacidad productiva y en parte por su estructura de costes, está en la raíz de las discrepancias sobre niveles de precios ${ }^{22}$.

¿Cuáles fueron los motivos que incitaron a estas tres sociedades a constituir una asociación comercial en fecha tan temprana? A primera vista, no había razones para ello, pues en ausencia de competidores cercanos (salvo en los puertos de mar el cemento importado, ya que cuando se inician las conversaciones el arancel no había sido modificado), cada sociedad podía actuar como monopolista puro en su mercado. No obstante, es posible apuntar varias razones que rentabilizaban los costes adicionales que entrañaba el funcionamiento y administración del cártel. La estrechez del mercado, debida a la apatía general de la economía y al hecho de que el cemento artificial era un producto nuevo, pudo ser un factor determinante para decidir a las fábricas a presentar un frente común. $\mathrm{Y}$, de igual forma, el deseo perentorio de reducir

21 Portland, Actas, ss. 11-4-1906.

${ }^{22} \mathrm{Si}$ ordenamos las sociedades con relación a su capacidad instalada, Asland eta la empresa con mayor poder negociador, seguida por Cementos Portland $y$, en última posición, por Rezola. La situación descrita en el texto puede representarse gráficamente de la siguiente manera:

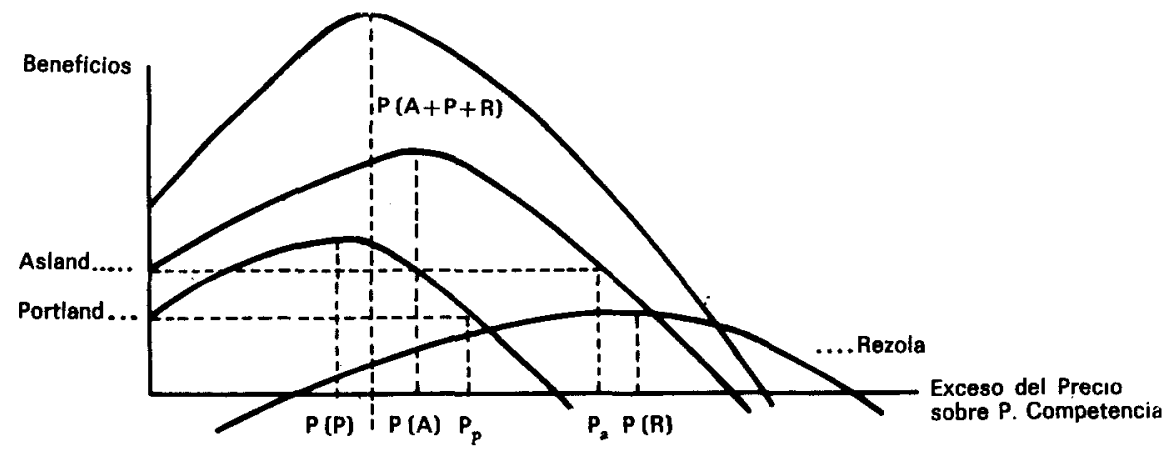

Al precio $P(A+P+R)$, los beneficios conjuntos son máximos. A la sociedad Asland le interesa un nivel de precios $P(A)$, puesto que maximiza sus beneficios. Por su parte, Portland resultaría más beneficiada si los precios fueran fijados en el nivel $P(P)$. Sin embargo, a Asland no le interesa que los precios excedan de $P_{a}$, porque sus beneficios serían entonces superiores en una situación competitiva. Por su parte, Rezola nunca aceptaría un precio inferior a $P_{r}$, pues ocasionaría pérdidas para ella. La única solución es que Asland y Portland fijen un precio entre $P_{r}$ y $P_{a}$ que beneficiara a Rezola. Este análisis está inspirado en Fog (1956), pp. 16 et passim. 
los costes unitarios al compartir gastos, como, por ejemplo, los de comercialización, al crearse agencias comunes de ventas, o al acercarse a una escala óptima de operaciones, sin duda, influyó en la decisión.

Una vez reformado el arancel en 1906, la existencia de importantes barreras de entrada en el sector permitió a la Unión de Fabricantes disfrutar de una existencia relativamente plácida por espacio de cinco años. En los consejos de las empresas asociadas solía darse cuenta puntual de lo tratado en la Unión acerca de precios o acerca de las notificaciones realizadas "por delicadeza» por algún miembro sobre concursos de obras ${ }^{23}$. Fue una constante del período la preocupación de las sociedades por disimular sus actuaciones. Para ello solían invitar a las otras sociedades a presentarse a los concursos con proposiciones más altas y evitar así un posible desprestigio del consorcio ante los consumidores ${ }^{24}$.

Todo pacto comercial es una incitación al fraude. Sin embargo, no hay constancia de que los socios de la Unión llevaran a cabo recortes secretos de precios en estos primeros años de vida del consorcio. Se adivina, no obstante, una preocupación mayor por parte de Asland para distanciarse de la política común y disponer en el medio plazo de una mayor capacidad de maniobra. En cuanto a las fábricas fuera de la Unión, éstas eran demasiado pequeñas para captar clientes suyos ofreciendo precios sistemáticamente menores. Tan sólo podían valerse de la ventaja geográfica de su emplazamiento ${ }^{25}$.

Los miembros del consorcio demostraron tener siempre una equilibrada

${ }^{23}$ Son numerosas las notificaciones realizadas en estos años. Voy a citar algunos de los casos más representativos. En 1906, Rezola informó a sus socios de su intención de vender $10.000 \mathrm{Tm}$. de su cemento con una rebaja de 8 pesetas sobre el precio fijado por la Unión. Su solicitud fue denegada en virtud del acuerdo sobre repartos equitativos entre miembros y por considerar que «esas rebajas excesivas pierden el mercado de la plaza donde se efectúan y aún se extienden sus efectos a otros en daño evidente de los intereses de la Union* (Portland, Actas, ss. 29-8-1906). Este periodo de concordia y buenas relaciones no estuvo, sin embargo, exento de algunas fricciones, como, por ejemplo, cuando Asland se excluyó temporalmente de la Unión por desacuerdos a la hora de realizar unas compensaciones. Sin Asland, la asociación no tenía razón de ser, por lo que bastó un mes para su reincorporación: «vióse con satisfacción que la Unión continuase sobre la base de fijar el precio», tal como Asland lo había requerido (Asland, Actas, ss. 28-1-1908, 28-2-1908).

${ }^{24}$ En el concurso para suministrar $4.000 \mathrm{Tm}$. para las obras de un pantano, Portland invitó a sus socios a presentar proposiciones más altas a la suya con objeto de evitar «el mal efecto que podría causar fuera sola nuestra proposición" (Portland, Actas, ss. 25-8-1908). Esta práctica de presentar a los concursos precios distintos se realizaba con frecuencia, siendo habitual que las fábricas asociadas sorteasen entre sí las propuestas con el fin de que weviten la apariencia de confabulación entre las mismas* (Portland, Actas, ss. 21-12-1909, 18-1-1910).

${ }^{23}$ En realidad, la única fábrica de competir con la Unión era la de Tudela-Veguín. En el concurso para las obras del pantano de la Pefia, Portland presentó una proposición al precio de 68,9 ptas/Tm. (tras el sorteo reglamentario, precio que dejaba un beneficio de $14 \mathrm{ptas} / \mathrm{Tm}$.). El concurso fue ganado por la fábrica de Oviedo, quien concurrió al pre- 
visión de los acontecimientos. Ya en 1909 se preocuparon por no elevar excesivamente los precios, lo que hubiera atraído a potenciales competidores: «las utilidades no han sido obtenidas en condiciones normales de la industria, sino que, siquiera en parte, son debidas a los beneficiosos efectos de la Unión de Fabricantes, que podrá durar más o menos tiempo, pero que no puede considerarse perdurable. [El consejo] juzga mucho más provechoso para la sociedad utilizar los efectos de la Unión en consolidarla y asegurarla un porvenir desahogado que no en aumentar los dividendos para hacer concebir esperanzas que quizá después no tengan realizaciones... El día en que la Unión quede disuelta ocupará una situación más ventajosa la sociedad que haya conseguido consolidarse mejor ${ }^{26}$.

Los acontecimientos que siguieron a 1911 dieron la razón a Portland. Sus ventas se estancaron en 1912 por efecto de la puesta en marcha de nuevas fábricas, a lo que vino a sumarse un ligero descenso en los beneficios medios ${ }^{27}$. Tampoco fueron favorables a los intereses de Asland los acontecimientos posteriores. La aparición de un competidor tan cercano como lo era Fradera $\mathrm{y}$, años más tarde, la llegada de la Auxiliar de la Construcción explica en buena medida el progresivo distanciamiento que se operó entre Asland y sus asociados en el segundo decenio.

En efecto, las nuevas fábricas catalanas tuvieron necesariamente que afectar a la demanda que hasta entonces Asland había monopolizado con ventaja sobre competidores de otras regiones. Es evidente que la política de precios mantenida por Asland, que respondía más a los intereses de la Unión que a los suyos propios, no era secundada por Fradera o la Auxiliar cuando se trataba de imponer una elevación de precios. Como es claro, a estas dos fábricas lo que les convenía era mantener invariables los precios con vistas a arrebatar clientes a su más cercano rival. Por la misma razón, se mostrarían, en cambio, dispuestas a recortar los precios para anular el alcance de cualquier iniciativa tomada por Asland en esa dirección ${ }^{28}$.

Aquí radica la gran diferencia entre Asland y las otras dos empresas de la Unión: ni Portland ni Rezola se enfrentaron jamás a competidores en sus

cio de 61,5 pesetas (Portland, Actas, ss. 18-1-1910). La ventaja de las fábricas pequeñas residía en el hecho de que, en sus propios mercados, no tenían que absorber los elevados gastos de transporte del cemento. En efecto, cuando el precio del transporte es muy alto con relación al valor del producto, su efecto es el de reducir la escala óptima de fabricación, colocando a las grandes fábricas en una posición desventajosa. Véase Scherer (1970), pp. 78-79.

${ }^{26}$ Portland, Actas, ss. 19-1-1909.

${ }^{27}$ Véase el gráfico 2, p. 341.

"Es decir, se supone que las fábricas no asociadas mantendrán la política más perjudicial posible a los intereses de Asland. Por esa razón, la curva de demanda a la que se enfrentaba Asland en el mercado catalán era del tipo quebrada, con la consiguiente discontinuidad de los costes marginales. 
mercados naturales, por lo que pudieron actuar en ellos como monopolistas. Por el contrario, Asland se enfrentaba en su mercado natural a una demanda de mayor elasticidad, lo que incitó a promover la formación de cárteles regionales. Dicha diferencia explica también la mayor agresividad demostrada por Asland en todos los mercados, dentro y fuera de España.

\section{LOS EFECTOS DE LA GUERRA MUNDIAL Y EL PERIODO COMPETITIVO, 1914-1926}

Las condiciones extraordinarias creadas por la Primera Guerra Mundial tuvieron un efecto desigual sobre la industria del cemento portland. A diferencia de lo ocurrido en otros sectores industriales que experimentaron serias dificultades por la escasez de materias y productos intermedios, el cemento fue totalmente inmune en este sentido al no depender del exterior.

Sin embargo, la guerra europea no fue motivo de prosperidad para el sector. La producción nacional de portland disminuyó a una tasa de 7,5 por 100 anual como reflejo de la debilidad de la demanda de consumo interior ${ }^{29}$. El encarecimiento de las materias primas, en particular hulla y yute, y el aumento de los salarios fue traspasado a los consumidores en la forma de aumentos espectaculares de los precios del cemento a pie de fábrica desde mediados de 1915. Por otra parte, el caos ferroviario fue causa de una falta de abastecimiento en varios mercados, lo que, sin duda, presionó los precios al alza.

En los primeros meses de 1914, las grandes fábricas se mostraban escépticas sobre si sería factible mantener el nivel de negocios de años anteriores: "... el resultado [de ese ejercicio] es verdaderamente excepcional, tan excepcional que no hemos conocido en el pasado otro que ni remotamente se le aproxima, ni podemos esperar con fundamento el logro en el porvenir de parecidos beneficios... Es de temer que esta excepcional situación del mercado desaparezca muy pronto.... ${ }^{30}$. El cambio de coyuntura al que se hace referencia era atribuido a la aparición de nuevas fábricas y expansión de la capacidad de otras, pero, desde luego, no a los acontecimientos internacionales que aún no se podían presagiar ${ }^{31}$. En agosto de 1914 se habla de la «situación anómala de los negocios» por haberse restringido el crédito ${ }^{32}$. $\mathrm{Y}$ en noviembre la Unión desestima la conveniencia de elevar sus precios por «con-

2 Véase Gómez Mendoza (1986).

30 Portland, Actas de las Juntas Generales (JG), ss. 30-1-1914.

"31 En concreto, Portland temía los efectos adversos que pudiera tener la expansión de capacidad en la fábrica de Matillas, así como el establecimiento de dos nuevas fábricas en Castillejo y Jelez Esquivas (ibidem).

32 Asland, Actas, ss. 29-8-1914. 
siderar pasada la oportunidad», prorrogando las bases de 1914 por otro año ${ }^{33}$.

Con el nuevo año, las expectativas empresariales mejoran tras una recuperación temporal de las ventas. Quizá en esta ocasión los socios se dejaron llevar por un excesivo optimismo, pues más que recuperación efectiva de la demanda interior, en realidad hubo sustitución de importaciones ${ }^{34}$.

A mediados de 1915, la coyuntura del mercado era de crisis: «... podemos esperar con tranquilidad la crisis de la industria cementera que necesariamente ha de surgir en plazo no lejano ${ }^{35}$. De nuevo, la responsabilidad sobre ese estado de cosas recae sobre la ampliación de la capacidad productiva. En el mes de julio, Asland y Portland, agobiadas por el encarecimiento de los inputs, proponen una elevación de los precios del cemento, lo que desestima Rezola ${ }^{36}$. Apenas transcurridos once días, la Unión acuerda elevar los precios en las plazas de Bilbao y Gijón ${ }^{37}$. Desde esa fecha hasta mediados de 1918 los aumentos de precios serán continuos, tal como sugieren los datos del cuadro 2.

\section{CUADRO 2}

La evolución de los precios del portland, 1916-1921

(Pesetas por Tm.)

\begin{tabular}{|c|c|c|c|}
\hline & Precio & Indice & Observaciones \\
\hline 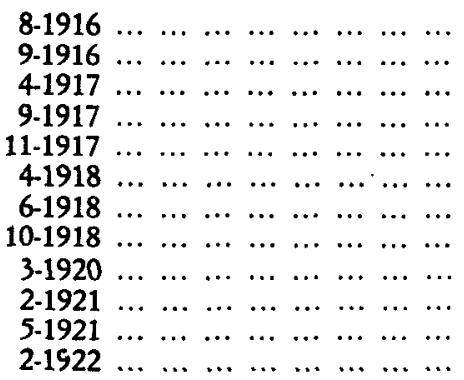 & $\begin{array}{r}80 \\
85 \\
90 \\
88 \\
100 \\
130 \\
150 \\
140 \\
130 \\
136 \\
120 \\
110\end{array}$ & $\begin{array}{l}100 \\
106 \\
113 \\
110 \\
138 \\
163 \\
187 \\
175 \\
163 \\
170 \\
150 \\
138\end{array}$ & Acuerdo Unión \\
\hline
\end{tabular}

FuENTES y notas: Se trata de precios a pie de la fábrica de Olazagutía sobre vagón, inclusive el envase. Cementos Portland, Actas (sesiones citadas en la primera columna).

${ }^{33}$ Portland, Actas, ss. 17-11-1914, 9-2-1914.

34 La evolución de las ventas en el primer trimestre fue calificada como «muy beneficiosa por el consejo de Asland (Asland, Actas, ss. 28-4-1915).

ss Portland, JG, ss. 30-1-1915.

36 Portland, Actas, ss. 13-7-1915.

${ }^{37}$ Ibidem, ss. 24-7-1915. 
Las decisiones de aumentar los precios fueron tomadas de forma individual por cada socio, si bien la Unión no había sido disuelta. Su operatividad disminuyó ante el encarecimiento de los materiales, los aumentos salariales y la creciente amenaza de nuevos competidores. Aun así, no parece que se produjeran enfrentamientos entre las fábricas asociadas ${ }^{38}$.

Sus bases fueron prorrogadas por otros dos años, aunque la posición de las fábricas era de un creciente escepticismo sobre sus ventajas: «... aunque en la forma actual no tiene ya dicha Unión razón de ser, continuamos manteniéndola, más que por los beneficios que aporta, por gratitud a los que nos proporcionó en tiempos pasados, y por mantener entre las tres sociedades relaciones cordiales que en lo venidero pueden servir de núcleo y punto de partida para una inteligencia que abarque mayor número de sociedades" ${ }^{39}$.

Para la industria del portland, el armisticio de 1918 fue una fecha clave para su desarrollo posterior. Coincidiendo con el fin de las hostilidades, desaparecían parcialmente las barreras de entrada que hasta ese momento habían preservado el mercado nacional a unas pocas fábricas. No sólo era posible adquirir otra vez la maquinaria en el extranjero, sino que fundamentalmente los capitales acumulados en otros sectores industriales podían ser transferidos hacia la industria cementera: «... por efecto de la guerra, está entrando en Bilbao mucho dinero del que una parte queda disponible para negocios...» Los numerosos proyectos para establecer nuevas fábricas en áreas que hasta entonces habían sido mal abastecidas en cemento, e incluso en áreas que caían dentro del mercado natural de algunas fábricas, constituyeron la variable fundamental para entender las vicisitudes del cártel de fabricantes durante la primera mitad de la década de 1920.

En el proceso se consolidó el distanciamiento entre Asland y sus socios. El enfrentamiento salió a la luz en el verano de 1918 al saberse que Asland proyectaba la instalación de una fábrica en Valladolid, mercado tradicionalmente servido por Portland y Rezola. Su reacción no se hizo esperar: «... la conducta de Asland perjudica los intereses de Portland y denota un espíritu absorbente que no se puede consentir dignamente... se autoriza a los comisionados a denunciar el contrato de la Unión de Fabricantes si las explicaciones que dé Asland respecto a su conducta pasada y futura no les satisfacen plenamente» ${ }^{41}$.

* Al menos en los años 1915 y 1916, «las circunstancias actuales del mercado nacional hacen improbable el choque de intereses encontrados entre los fabricantes» (Portland, $J G$, ss. 29-1-1916).

3o Portland, JG, ss. 27-1-1917, y, también, Actas, ss. 20-11-1917.

to Portland, JG, ss. 27-1-1917.

${ }^{41}$ El incidente de Valladolid se resolvió dos meses más tarde, al dar seguridades Asland de que todo había respondido a una iniciativa suya para conocer desde dentro los 
Como consecuencia de este enfrentamiento en el seno de la Unión, se favoreció la constitución de cárteles regionales en sustitución de la primitiva asociación de 1906. Desde ese momento, Portland estrechará definitivamente lazos con Rezola, y a propuesta de ésta se formó una Asociación Profesional de Material Hidráulico del Norte de España ${ }^{42}$. Por su parte, Asland ocupó la presidencia de la Agrupación de Fabricantes de Materiales Hidráulicos, constituida en 1919 en Barcelona, y alentó la creación de otro organismo, esta vez para canalizar. los excedentes de cemento hacia mercados exteriores ${ }^{43}$.

Mientras que se creaban estas asociaciones regionales, hubo gestiones encaminadas a salvar a la primitiva Unión o lo que de ella quedaba. El problema de fondo era que el consorcio había dejado de ser representativo al quedar excluidos gran número de fabricantes, por lo que se planteaba o su disolución definitiva o su reforma ${ }^{44}$. En mayo de 1920 se celebró una reunión en Madrid para «tratar de la disolución... intentando antes hacer algo para no romper del todo» ${ }^{45}$ Asland era partidaria de formar un gran cartel de fabricantes que se encargase de la venta del cemento artificial con intervención de la banca con vistas a aligerar a las fábricas del capital circulante requerido por la comercialización ${ }^{46}$. El principal obstáculo lo constituía la resistencia por parte de la casa Fradera a integrarse en el futuro cártel ${ }^{47}$. Ante la falta de acuerdo Asland declaraba disuelta la Unión en mayo de 1920, hecho que no recogen las actas de Portland, pero sí la memoria anual ${ }^{48}$. Tras catorce años de vida, el oligopolio del cemento artificial quedaba temporalmente suprimido.

De esta forma se entra en una nueva fase caracterizada por una acentuación de la competencia y una mayor compartimentalización del mercado interior. Las empresas cementeras volvieron a dar muestras de una envidiable capacidad de ajustarse a todas las situaciones. Las expectativas empresariales eran buenas, «pues la concurrencia comercial fomentará el consumo de ce-

planes de una sociedad independiente de aquella ciudad (Portland, Actas, ss. 27-8-1918, 10-10-1918).

${ }^{42}$ Portland, Actas, ss. 23-8-1919.

43 Asland, Actas, ss. 30-6-1919, 30-10-1919.

* 4... Siendo ineficaz [la Unión] para evitar la competencia porque es tan importante la producción de las fábricas libres como la de las unidas... no podemos predecir cuál será el resultado de estas gestiones que están en sus comienzos y que han de ser largas y laboriosas» (Portland, $J G$, ss. 31-1-1920).

45 Portland, Actas, ss. 18-5-1920.

4 Asland, Actas, ss. 23-12-1919.

${ }^{47}$ Huici, presidente de Cementos Portland, hizo una gestión personal con Fradera para lograr su aceptación, fracasando en el intento (Portland, Actas, ss. 29-5-1920).

${ }_{48}$ «Las gestiones fracasaron porque hubo fabricante que se propuso indudablemente disfrutar de todas las ventajas sin tener que soportar los inconvenientes quedándose al margen de ella, $y$ nosotros [Portland] nos negamos rotundamente a aceptar tal situación desventajosa y humillante. $\mathrm{Y}$ no teniendo razón de ser, se dio caducada en mayon (Portland, $J G$, ss. 27-1-1921). 
mento al repercutir en el precio, y siendo así resulta evidente la conveniencia de una ampliación...» ${ }^{49}$. Tan súbito convencimiento de que lo mejor eran las fuerzas del mercado tras años de restricción de la competencia sólo podía explicarse por un intento deliberado por hacer menos atractiva la entrada a potenciales inversores deprimiendo los precios hasta alcanzar el equilibrio competitivo. Por otro lado, para preservar el nivel de beneficios, las grandes fábricas debían actuar sobre sus costes a través de una política de ampliación de capacidad. En definitiva, se trataba de sacar el máximo partido a las economías de escala aumentando la producción hasta un tamaño óptimo del establecimiento.

La nota característica del período 1921-1926 fue la baja sostenida de los precios del cemento artificial. Los fabricantes achacaron ésta a los estragos de la competencia, provocada, a su vez, por un elevado índice de sobreproducción. La aplicación de un gravamen de 50 pesetas por tonelada de cemento exportada a ultramar, que cerró el mercado exterior a los fabricantes nacionales, explica el exceso de oferta. Tras laboriosas gestiones por parte de las grandes fábricas, el gravamen fue finalmente suprimido, y a modo de compensación, ante la amenaza de importaciones masivas producidas por la crisis postbélica internacional, el gobierno decidió doblar el arancel que había estado vigente desde 1906. El nuevo arancel hizo más atractiva la inversión en el sector, favorecida, a su vez, por la política de la Comisión Protectora de la Industria Nacional. Consistía ésta en conceder ayudas monetarias a las sociedades establecidas en las regiones centrales para ampliar capacidad o en la alternativa para ayudarlas a establecerse. Significaba luz verde para el desarrollo de un nuevo foco productivo para abastecer el importante mercado de Madrid, hasta entonces monopolizado por los miembros de la Unión ${ }^{50}$.

Como se ha visto en el cuadro 2 , el descenso de los precios se inició a comienzos de 1921. Coincidió en el tiempo con una reducción de los beneficios medios de la empresa Portland (véase gráfico 2) ${ }^{51}$. Ante las nuevas condiciones del negocio, la respuesta de los grandes fabricantes revistió una doble forma: en un primer momento, que se prolongó hasta 1926, se entregaron a

49 Portland, JG, ss. 26-1-1922.

${ }^{30} \mathrm{El}$ proyecto fue duramente combatido por las fábricas del litoral. La idea de Sánchez de Toca era que el consumidor de la región central no se viera gravado por el «sobreprecio que representa la carestía del transporte y la anormalidad del mismo... que perdurará varios lustros. Por tal razón, entiende que el consumo del interior debe ser atendido por la oferta interior, quedándoles a las fábricas del litoral el recurso de la exportación» (Asland, Actas, ss. 29-4-1922).

${ }^{51} \mathrm{La}$ caída de los beneficios se debía a que ula competencia se inicia y se ha de agudizar porque no en balde han entrado en funcionamiento dos nuevas fábricas, una en Bilbao y otra cerca de Sevilla, y están construyendo una en Toral de los Vados y otra en Madrid» (Portland, JG, ss. 28-1-1924). 


\section{GRAFICO 1}

Evolución de la producción nacional y ventas de la Sociedad de Cementos Portland, 1907-1935

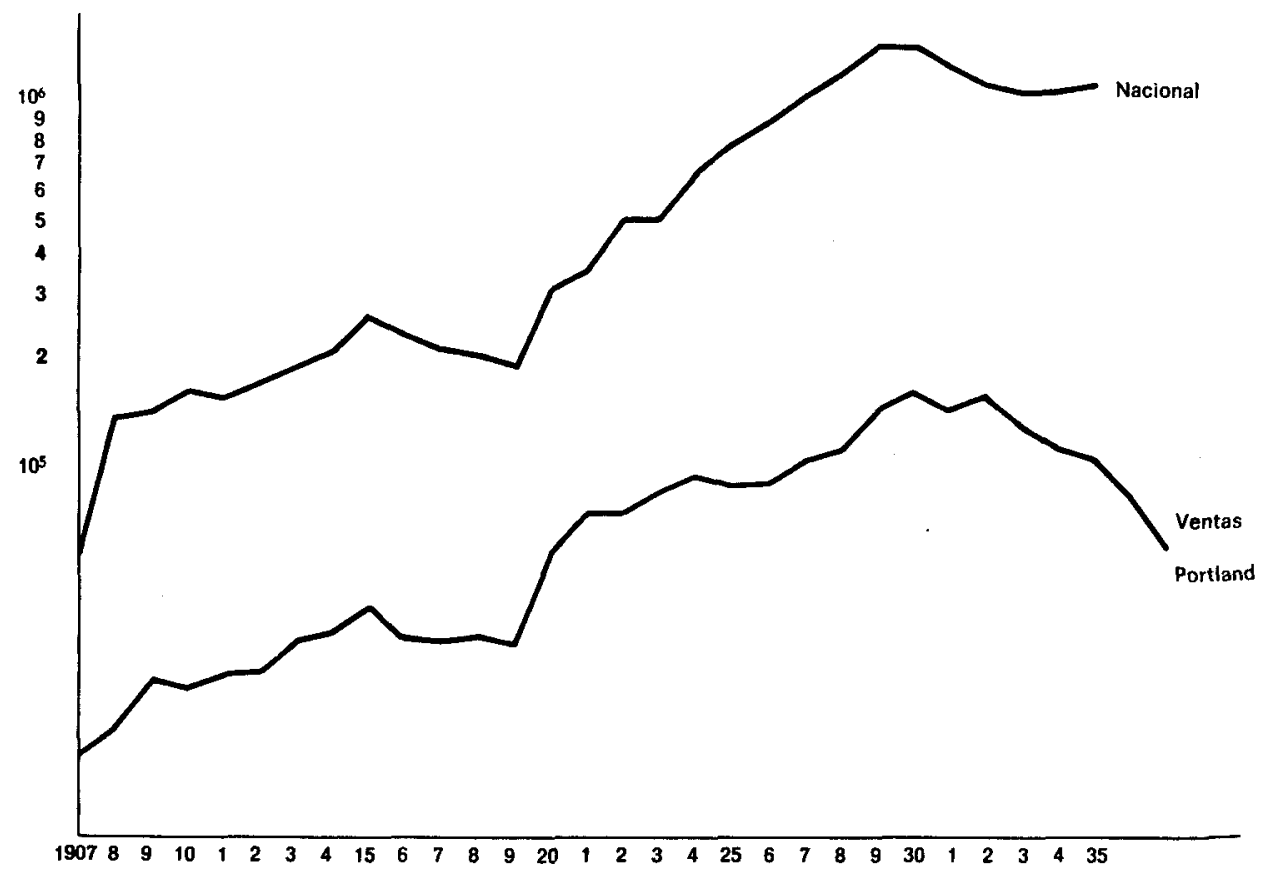

Fuente: Portland, Actas.

los mecanismos del mercado ajustándose a través de una política expansiva, bien ampliando la capacidad de sus fábricas viejas, bien estableciendo nuevas o absorbiendo empresas en dificultades financieras. En una segunda etapa, apremiadas por lo que llevaba trazas de convertirse en una reducción drástica de los beneficios, intentaron reagruparse en torno a un nuevo cártel para restringir la competencia y estabilizar los precios.

La competencia entre grandes y pequeñas fábricas alcanzó de lleno a los antiguos socios de la Unión. Más sensible a la competencia establecida en los mercados del litoral, Rezola lamentaba la ofensiva comercial de marcas como «Asland» y «Sansón», en Andalucía y Levante. De igual forma, para frenar la entrada de cemento catalán y leonés en el mercado castellano, Rezola y Port- 


\section{GRAFICO 2}

Evolución de los beneficios en pesetas/toneladas métricas de Cementos Portland, 1910-1937

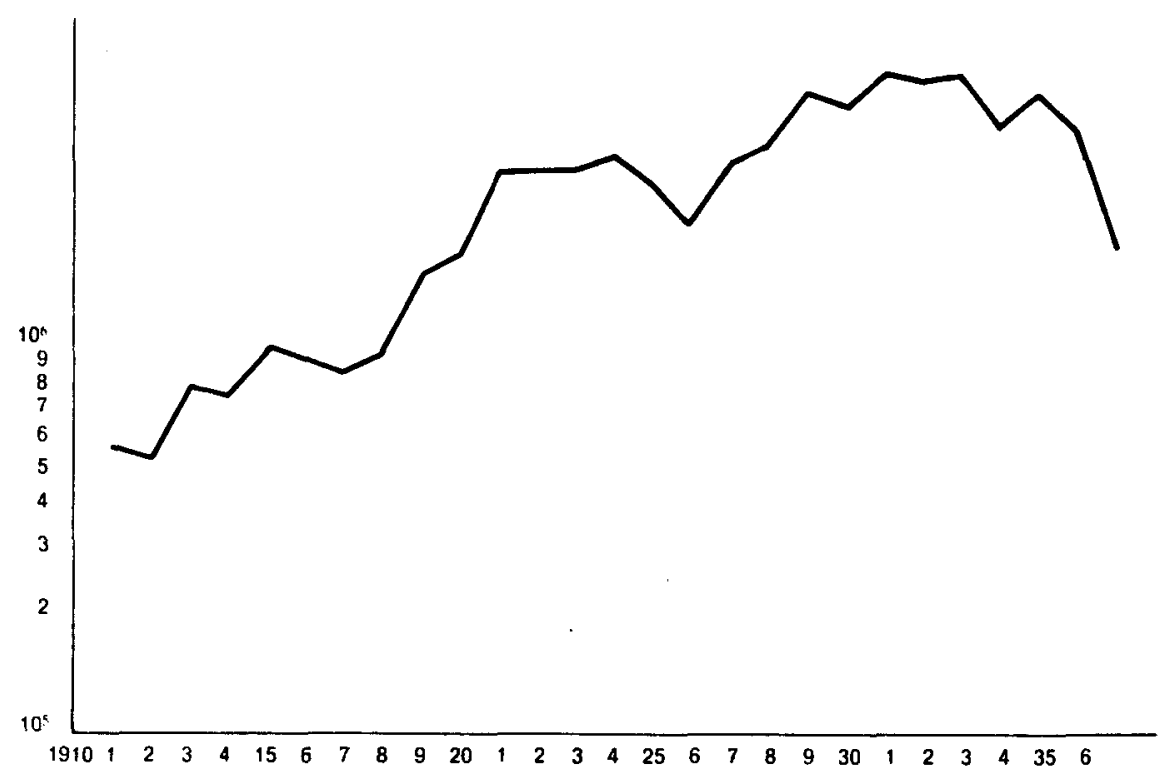

Funerte: Portland, Actas.

land establecieron un sindicato de ventas ${ }^{52}$. Los recelos mutuos entre antiguos socios llegaron a un punto álgido en 1923 cuando Portland rechazó una propuesta de las fábricas catalanas para fijar precios comunes en el mercado de Zaragoza, «pues hay muchas razones por las que la sociedad saldría material y moralmente perjudicada» ${ }^{53}$.

Tal como se ha señalado, la primera estrategia elegida por las grandes fábricas consistió en aumentar su producción, bien a través de la expansión interna, bien mediante la fusión con empresas menos afortunadas. Los ejemplos de una y otra actuación son numerosos, si bien a veces se trataba, en realidad, de meros proyectos nunca realizados que, sin embargo, producían el efecto apetecido de desincentivar a posibles competidores. Si tomamos Asland,

s2 Portland, Actas, ss. 19-1-1922, 2-4-1925.

33 Portland, Actas, ss. 24-4-1923. 
encontramos que esta sociedad acarició sucesivamente los siguientes proyectos: en 1921, montar una fábrica en Sevilla, proyecto abandonado posteriormente ante el establecimiento en Morón de una planta perteneciente a la Sociedad Andaluza de Cementos Portland; en el mismo año, gestiones para adquirir la fábrica de la Constructora Bilbaína, lo que también quedó sin efecto; en 1924, establecer una filial en Villaluenga (provincia de Toledo), que entró en funcionamiento dos años más tarde; en 1925, adquirir una fábrica en Bilbao, lo que dio lugar al año siguiente a la constitución de la filial Asland de Bilbao; por último, en 1926, gestiones para adquirir la fábrica de Málaga, sin resultados ${ }^{54}$. Con una actitud menos agresiva, Portland también se planteó una estrategia similar: en 1922, establecer una fábrica en Olmedo, que nunca se llevó a la práctica; en ese mismo año, establecer otra fábrica en Segovia, proyecto que también fue abandonado posiblemente ante la política expansiva de Asland en el mercado central; en 1925, otro proyecto de colaboración en el montaje de una fábrica, esta vez en Morata de Jalón, también sin resultados, y, por último, en 1926, la adquisición de la fábrica de Ziurrena en la ría de Bilbao ${ }^{55}$.

Merece la pena detenerse a considerar los motivos para embarcarse en una estrategia expansiva cuando la industria atravesaba una fase de sobreproducción. Las manifestaciones tan loables hacia las virtudes de la competencia no fueron, sin duda, los verdaderos motivos que llevaron a las grandes fábricas a aumentar su capacidad. Antes bien, su comportamiento es más cercano al de un oligopolista que lucha por recuperar su cuota de mercado que al de una empresa competitiva. El trasfondo de una operación de compra de una fábrica en la ría de Bilbao por parte de Asland y Portland contiene elementos interesantes para aclarar los motivos y beneficios de una fusión.

Las negociaciones para la adquisición de la fábrica de Ziurrena se prolongaron por dos años a causa del interés de ambas sociedades por hacerse con ella, aunque las motivaciones eran distintas. Tras establecerse en la región central, Asland necesitaba consolidar su presencia en los mercados septentrionales apremiada por las dificultades que encontraba en el mercado de Barcelona. En cambio, para Portland la operación era vital para romper el bloqueo que, de otra forma, Asland hubiera impuesto en torno suyo.

La fábrica de Ziurrena estaba ligada al Crédito de la Unión Minera, a quien adeudaba 2.000.000 de pesetas. La desaparición del Crédito había colocado a la empresa cementera en una situación crítica. El consejo de Portland se ocupó por vez primera del asunto relativo a una posible fusión en

s4 Asland, Actas, ss. 31-1-1921, 6-6-1921, 28-4-1924, 30-11-1925, 28-2-1926, 12-8-1926, 18-12-1926.

ss Portland, Actas, ss. 18-10-1922, 13-12-1922, 1-3-1923, 2-4-1925 y 4-8-1926. 
abril de 1925, aunque no se detallaron el alcance de las negociaciones mantenidas. En noviembre, Asland adquirió 2.000 obligaciones hipotecarias de Cementos Ziurrena, colocándose en una posición inmejorable para absorber a esta sociedad ${ }^{56}$. La operación realizada por Asland fue descubierta por Portland nueve meses más tarde: «... no puede convenir a Portland que Asland se quede con Ziurrena porque esto equivaldría a establecer un bloqueo en torno a Olazagutía con propósito que sólo Asland conoce» ${ }^{57}$. Al hacer pública Portland su intención de presentarse como postor para la adquisición de Ziurrena, Asland le ofreció una explotación conjunta del establecimiento ${ }^{58}$. Portland rechazó el ofrecimiento, alcanzándose finalmente un acuerdo entre ambas sociedades por el cual Asland renunciaba a Ziurrena «ante el temor a encontrarse con un capital invertido en una industria gobernada y dirigida por un competidor" ${ }^{59}$.

Desde la perspectiva de Portland, la operación fue ventajosa por varios motivos. Primero, porque la fábrica de Ziurrena constituía una «arma de defensa y ataque contra las otras fábricas» al restringir la competencia en el mercado del litoral Norte. Segundo, porque el precio de adquisición (3,3 millones de pesetas) fue inferior en casi dos millones a lo que hubiera costado en 1926 establecer una fábrica de' similares características, y posiblemente con peores comunicaciones. Es decir, con esta adquisición, Portland estaba en condiciones de alcanzar la capacidad de producción deseada a un coste menor. Tercero, porque la expansión de capacidad se lograba sin alterar el equilibrio del mercado, es decir, sin aportar nuevos elementos que hubieran desencadenado una nueva baja en el precio. del cemento. Cuarto, porque en el acuerdo establecido con Asland, ésta se comprometía a no realizar aumentos de capacidad en su factoría bilbaína. Y, quinto, porque ante las perspectivas de establecer un nuevo cártel, era aconsejable ampliar la capacidad de cada fabricante, lo que equivalía a un mayor poder negociador ${ }^{60}$.

56 Asland, Actas, ss. 30-11-1925.

57 Portland, Actas, ss. 4-8-1926.

so .... realizando Portland trabajos muy eficaces que no nos conviene combatir con demasiado empeño porque de ellos se seguiría una rivalidad y competencia irreductibles en el norte y centro de España» (Asland, Actas, ss. 12-8-1926).

${ }_{50}$ Dentro de su política conciliadora, Asland ofreció a cambio de su renuncia que Portland se hiciera cargo de su opción para la adquisición de los créditos de la Unión Minera contra Ziurrena, de sus acciones y de la comercialización de la producción de la fábrica de Basurto (Asland, Actas, ss. 29-10-1926).

${ }^{\infty}$ Portland, JG, ss. 27-10-1926. 


\section{LOS CARTELES REGIONALES DE 1926}

La estrategia de restringir la competencia a través de los mecanismos del mercado fue complementada por algunas grandes fábricas por la conocida estrategia de aglutinar a los principales fabricantes en un consorcio nacional que estabilizara los precios y fijara cuotas de ventas para cada uno. La razón principal para entender este giro en la política empresarial la encontramos en la evolución de los beneficios medios. Como puede observarse en el gráfico 2, los beneficios por tonelada vendida de cemento fueron decrecientes entre 1922 y 1926 , lo que respondía a una caída más rápida de los precios del cemento que de los costes medios de producción. Y ello ocurrió a pesar de los esfuerzos de los grandes fabricantes por responder al reto del mercado. Intentaron ajustarse a las nuevas condiciones realizando economías de escala e introduciendo nuevos procesos técnicos que sustituían materias primas y trabajo por capital ${ }^{61}$.

La pérdida de mercados por efecto del aumento de la competencia explica, por lo tanto, el cambio de actitud entre los grandes fabricantes ${ }^{62}$. Estos habían experimentado dificultades crecientes para colocar sus productos en mercados hasta entonces desprovistos de un productor local, e incluso sus propios mercados «naturales» habían resultado amenazados por la aparición de algún competidor. De este modo, Cementos Portland vio cómo, desde 1923, otras fábricas captaban parte de su clientela en las provincias de Alava, Logroño y Zaragoza y cómo sus ventas decrecían en Pamplona en provecho de pequeños fabricantes ${ }^{63}$.

Aunque Asland estaba más acostumbrada que Portland a la competencia, dentro de su radio de acción sufrió, sin embargo, un importante revés en estos años: cuando tenía establecido un preconvenio con las obras del Gran Metropolitano de Barcelona, el contrato fue otorgado a otra fábrica local ${ }^{64}$. La decepción sufrida hubo de afectar necesariamente al esquema de Asland sobre

"1 Gómez Mendoza (1986a).

2 Es preciso señalar, una vez más, que la situación del mercado de portland entre 1921 y 1926 distaba mucho de la competencia perfecta, siendo más propio hablar de un relajamiento de las prácticas restrictivas. Como veremos en el apartado de conclusiones, las empresas cementeras siguieron aplicando durante esos cinco años una política de discriminación de precios, lo que denota la existencia de un cierto control de mercado por su parte.

${ }^{63}$ En cada ocasión, la competencia forzó a Portland a rebajar sus precios a pie de fábrica: «... no es conveniente... un precio tan alto pues da margen a nuestros competidores para combatirnos con ventaja en nuestra zona... (Portland, Actas, ss. 19-8-1925). $\mathrm{Y}$ en relación con la competencia en el mercado de Vitoria, «... no puede consentirse que otras marcas vengan a arrebatarnos este mercado que hasta ahora hemos monopolizado... (Portland, Actas, ss. 2-2-1926, 19-2-1926, 3-4-1926).

4 Asland, Actas, ss. 22-8-1922, 30-1-1923. 
su condición de empresa dominante en la industria del portland. De ahí sus gestiones por espacio de tres años para constituir una Unión de Fabricantes de Cataluña.

Tras el incidente del Metropolitano, Asland desempeñó sucesivamente dos bazas encaminadas a acabar con la competencia. A comienzos de 1923 estableció un acuerdo con la Auxiliar y Fradera para unificar precios en el mercado de Barcelona ${ }^{65}$. Dos meses después, Asland se felicitaba de «los buenos resultados obtenidos en Cataluña" debidos a un «aumento extraordinario de las ventas», lo que, sin dudar, atribuía al convenio recién estrenado ${ }^{66}$. Ante las buenas perspectivas, en septiembre de 1923 se aprobaron las bases definitivas de una Unión de Fabricantes de Portland de Cataluña (UFPC) ${ }^{67}$.

Creyendo estabilizada definitivamente la situación en el mercado catalán, Asland acometió en seguida la segunda parte de su plan consistente en ampliar la UFPC a toda España ${ }^{68}$. Dichas gestiones fracasaron por dos motivos. Primero, por la oposición de los fabricantes del centro a verse atrapados en un sindicato de ventas con la mayor fábrica de España. De ahí la premura demostrada por Asland para buscar un emplazamiento adecuado para su nueva fábrica de Villaluenga. $Y$, en segundo lugar, porque los pactos de Barcelona eran mucho más frágiles de lo que Asland había supuesto. En noviembre de 1924, la Auxiliar de la Construcción denunció el convenio y optó por abandonar la UFPC ${ }^{69}$.

La dificultad para reconstruir el cártel del cemento prueba que en las condiciones del mercado del primer quinquenio de 1920 el principal obstáculo era la desconfianza entre fabricantes. Mientras que no se lograron acuerdos cuidadosamente trazados, toda fábrica al margen de los pactos estaba en condiciones de cosechar mayores beneficios aplicando una política de recortes sistemáticos en los precios ${ }^{70}$.

Hubo que esperar a mediados de 1926 para que la Auxiliar conviniera en integrarse en la UFPC. Se unificaron los precios y se acordaron los siguientes cupos de ventas: Asland, un 48,84 por 100; Auxiliar, un 29,16 por 100, y Fradera, el restante 22 por $100^{71}$. Además de factores ya señalados, como el recorte en los beneficios, el cambio de actitud de la Auxiliar pudo deberse

${ }^{65}$ Ibidem, ss. 3-5-1923.

* Ibidem, ss. 27-7-1923.

67 Ibidem, ss. 28-9-1923, 28-2-1924.

so Ibidem, ss. 27-3-1924.

* Esta denuncia no impidió una colaboración estrecha entre Asland y la Auxiliar, junto con algunas casas de banca, con objeto de formar una sociedad para la construcción de carreteras de hormigón armado. En diciembre de 1924 se reiniciaron los contactos para rehacer la Unión sobre otras bases (Asland, Actas, ss. 5-12-1924, 26-1-1925).

${ }^{70}$ Véase, más adelante, $\$ 6$.

71 Asland, Actas, ss. 28-6-1926, 12-8-1926. 
al hecho de que Cementos y Cales Freixa, empresa fabricante de cementos naturales, inició la fabricación de portland en dicho año ${ }^{72}$. Tampoco en esta ocasión pudo redondearse el acuerdo, pues Fradera se las ingenió para quedar en una situación de interinidad ${ }^{73}$. Al igual que había ocurrido tras la firma del convenio de 1923 , las ventas de Asland se intensificaron ${ }^{74}$. También se preveía que la unión de todos los fabricantes catalanes fuera una realidad en una fecha relativamente cercana ${ }^{75}$.

En otras regiones españolas se habían llevado a cabo procesos similares al de Cataluña. A comienzos de 1926, una desconocida agrupación de fabricantes había promovido la formación de una central de ventas. La propuesta fue mal recibida por sociedades como Cementos Portland escudándose tras dos argumentaciones. En primer lugar, argüía Portland que era «... peligroso el establecimiento de la Central porque siempre han mirado los consumidores con desafecto esas inteligencias que significan una imposición para ellos y porque, gozando el cemento de una protección arancelaria bastante elevada, la centralización de las ventas podría dar lugar a concesiones arancelarias que estarían justificadas por tan patente confabulación» ${ }^{76}$. Más adelante añadía que «... estima difícil, peligrosa y complicada una sindicación en las actuales circunstancias...» ${ }^{n}$. El segundo argumento esgrimido por Portland era el de la desconfianza: una plena efectividad no podía lograrse mientras que determinados fabricantes optaran por mantenerse al margen de la Central. En concreto, Portland acusaba a Asland, entre otros, quien había optado por salirse de la Agrupación de Fabricantes Nacionales de Cemento, lo que colocaba automáticamente a Portland en una situación desventajosa al no gozar de la libertad de actuación ${ }^{78}$.

${ }^{72}$ Cementos y Cales Freixa, Actas, ss. 8-5-1926. «Freixa debía mantener el precio [del portland] algo más bajo que las otras casas como era un producto aún no afianzado en el mercado por el poco tiempo de vida que llevaba. Este afianzamiento sería difícil si no se ofrecía un precio ventajoso...» (ibidem, ss. 28-10-1926).

${ }^{73}$ Asland, Actas, ss. 29-10-1926.

${ }^{74}$ «La Central de Ventas sigue su marcha con inmejorables resultados» (Asland, Actas, ss. 28-1-1927).

${ }^{73}$ Según se hizo constar en las reuniones del Consejo de Freixa, esta sociedad fue obligada por otras fábricas a integrarse en la Central: «... se expuso el decidido empeño que ponian los directores de la Central de Ventas para que Cementos Freixa se sumase a su obra, insinuando incluso la posibilidad de acudir a medidas coercitivas en el caso de que por convencimiento amistoso no lograran su iniciado empeño..." (Freixa, Actas, ss. 3-3-1927).

${ }_{76}$ Portland esperaba que no fuera necesario llegar a la perentoria necesidad de ese acuerdo y que, en su lugar, «los fabricantes rectifiquen su conducta ante el convencimiento de que el camino que han emprendido sólo puede conducir a la ruina de la industria cementera nacional» (Portland, Actas, ss. 23-1-1926).

7 Sin embargo, el Consejo de Portland no quería «aparecer como irreductiblemente opuesto" (Portland, Actas, ss. 17-2-1926).

7 Por otro lado, Asland había perdido interés por un cartel nacional ahora que con- 
La decisión tomada por Asland fue probablemente una medida de fuerza para forzar a las sociedades más reacias a integrarse en un cártel. Era evidente que la generalización de una guerra de precios sólo podía beneficiar en el medio plazo a las fábricar con menores costes y de más alta productividad. He mostrado en otro lugar que existía una correlación significativa entre escala y productividad, por lo que sólo los grandes fabricantes estaban en condiciones de sobrevivir a la intensificación de la competencia ${ }^{79}$.

Tras eliminar los últimos aspectos conflictivos, los grandes fabricantes acordaron a fines de 1926 hacer cesar la competencia y estabilizar los precios del cemento. Como ya he señalado, la «irreductible oposición» de las fábricas de la región central hizo que se desestimase la idea de constituir un cartel que abarcara todo el territorio nacional. En su lugar se optó por la constitución de uniones regionales siguiendo el modelo catalán. Entre otros, se estableció un cártel para la zona Levante/Sur y otro para el mercado Norte/Noroeste. En el primero se integraron, por parte catalana, Asland, Auxiliar y Fradera, y, por parte levantina, la Compañía Valenciana de Cementos Portland «Raf». A cambio de la mitad de las ventas en el mercado valenciano, «Raf» se comprometió a no realizar una proyectada ampliación de capacidad ${ }^{80}$. En el cártel de la zona Norte se integraron las siguientes sociedades: Portland, Rezola, Asland Bilbaíno, Lemona, Ziurrena, Tudela Veguin y Cosmos ${ }^{81}$. Los acuerdos establecían precios únicos en todos los mercados, punto éste en el que radicaba principalmente el desacuerdo de los fabricantes de Madrid deseosos de recibir un precio sombra, equivalente al sobreprecio que implicaba el transporte del cemento del litoral hasta el mercado central ${ }^{82}$. La exclusión definitiva de los fabricantes de Madrid llevó a calificar el acuerdo de 1926 como «frágil» $\mathrm{y}$ «poco consolidado» ${ }^{83}$.

\section{PROSPERIDAD Y CRISIS EN LA INDUSTRIA DEL PORTLAND, 1927-1935}

A efectos de exposición, conviene subdividir este período en tres fases. Durante la primera, 1927 a 1929, lo más destacable fue, por un lado, una expansión de la producción de cemento artificial. En 1930 se alcanzó un má-

taba con una fábrica en Villaluenga. En cuanto a la indecisión de Portland, ésta tenía su origen en una cláusula que obligaba a los firmantes del pacto a satisfacer una determinada cantidad por los sacos vacíos (Portland, Actas, ss. 3-4-1926, 22-4-1926).

${ }^{79}$ Gómez Mendoza (1986a).

${ }^{20}$ Asland, Actas, ss. 27-7-1927.

" Portland, Actas, ss. 6-11-1926.

32 Véase $\$ 6$.

*3 Portland, JG, ss. 26-1-1927. 
ximo histórico, registrándose una tasa de crecimiento superior a un 13 por 100 anual desde 1926, reflejo, a su vez, de una expansión, incluso más rápida, de la demanda interior. Esta última se vio estimulada por el auge en las obras públicas, en las obras residenciales y por el efecto de las exposiciones universales. Las ventas de cemento «Cangrejo» fueron máximas en 1930, creciendo a una tasa superior a un 15 por 100 anual desde $1926^{84}$. El segundo aspecto destacable de esta fase fue una creciente intervención pública en el oligopolio del cemento artificial, con una doble manifestación: como cliente y como regulador de su actividad ${ }^{85}$.

La segunda fase abarca únicamente el año de 1930. A pesar de que los niveles de producción y ventas tocaran techo, los beneficios medios decrecieron, tal como puede observarse en el gráfico 2, para Portland, lo que, sin duda, también ocurrió para otras sociedades.

En la tercera fase, que cubre la primera mitad de la década de 1930 , los fabricantes se afanaron por solucionar de forma definitiva los problemas planteados en el sector por la recesión de la demanda de consumo de cemento artificial. Sin embargo, al menos por lo que se refiere a la sociedad Portland, la tendencia de los beneficios medios fue creciente, extremo compartido probablemente por otras empresas. Por consiguiente, no parece adecuado referirse a este período como uno de crisis generalizada en el sector.

\section{a) La política económica de la Dictadura y el oligopolio del cemento}

Al aceptar las fábricas de portland establecer las bases para formalizar acuerdos regionales en 1926, aun si el equilibrio alcanzado fue precario, quizá intentaban presentar un frente común ante lo que presagiaban podía convertirse en años dorados para la industria. No hay que olvidar que en las previsiones más pesimistas se esperaba que las obras hidráulicas y ferroviarias se prolongaran por espacio de al menos diez años.

Para conocer las repercusiones reales del impulso dado a las obras públicas, sería necesario estudiar caso por caso la localización de los principales focos de consumo en relación con el emplazamiento de las fábricas de cemento artificial. Dadas las características del mercado, y en particular el sesgo en la distribución geográfica de los establecimientos a favor del litoral de la mitad norte de la Península, es probable que la industria existente en 1926 no estuviera en condiciones de satisfacer adecuadamente la demanda de las nuevas

34 Sin embargo, las ventas en el mercado nacional tocaron techo en 1929. En 1930 habían decrecido en unas $150.000 \mathrm{Tm}$., lo que representaba un 8,6 por 100 .

os Sería conveniente conocer la participación de la demanda pública en el consumo to tal para determinar en qué medida el sector público actuó durante estos años como un monopsonista. 
obras. Podemos contrastar esta sospecha mediante la distribución por puertos de las importaciones de cemento artificial realizadas en el transcurso de 1929. Las aduanas marítimas andaluzas recibieron un 56 por 100 del cemento importado, destacando Sevilla, por donde se recibió un 39 por 100. En comparación con estos porcentajes, puede verse que la capacidad instalada por las tres fábricas ubicadas en Andalucía representaba sólo un 13,6 por 100 de la capacidad nacional, lo que denota un claro desequilibrio entre producción y consumo $^{86}$. Este desequilibrio explica, a su vez, algunas de las medidas adoptadas por la Administración en aquellos años: por un lado, la propia franquicia arancelaria de 1929 y, por otro lado, la política de ampliación de las fábricas existentes y construcción de nuevas. De este modo, la iniciativa pública de fomento de las obras públicas, lejos de mejorar la situación del sector cementero, agravó, en el medio plazo, el exceso de capacidad que venía experimentando desde 1920. No sólo impulsó el establecimiento de nuevas plantas productoras, sino que éstas fueron por lo general de escala pequeña ${ }^{87}$.

Los acuerdos alcanzados en 1926 fueron puestos a prueba en varias ocasiones por las tensiones que en seguida se desataron entre los principales fabricantes ${ }^{88}$. Pero la mayoría reafirmó su voluntad de atenerse a lo pactado como único medio para detener la caída de los precios: «... [la Unión] ha evitado el derrumbamiento total de los precios que venía a pasos agigantados a causa de la competencia.... ${ }^{89}$.

Es necesario considerar con algún detalle la intervención pública en el sector cementero, así como la actitud de los grandes fabricantes a su respecto. Con anterioridad a la cartelización del sector, promovida desde el Gobierno en 1929, éste había venido ejerciendo un control sobre las operaciones del sector. La creación del Comité Regulador de la Producción Industrial en 1926 había significado que todas las ampliaciones de capacidad y creación de nuevas fábricas habían de contar con autorización oficial ${ }^{90}$. En los meses siguientes, el Gobierno urgió a los cementeros a poner fin a sus desaveniencias mediante la constitución de una agrupación nacional. Un sector de los fabricantes

* Todos estos porcentajes están basados en la información proporcionada por Ministerio de Fomento (1929), p. 45.

87 Entre 1926 y 1934 se duplicó la capacidad instalada, según se desprende de los datos proporcionados por De Miguel (1935), p. 156. En 1931, Asland inauguró su filial de Córdoba, con $70.000 \mathrm{Tm}$. de capacidad anual. Esta planta era la mayor de las seis plantas creadas después de 1926.

"Por ejemplo, «Cosmos» jugó en 1927 la baza de abandonar la Unión si ésta no le otorgaba el suministro de los Saltos del Duero (Portland, Actas, ss. 24-10-1927, 3011-1927).

"La Central de Ventas del Norte fue prorrogada en 1927 por tres años. A la fábrica de Olazagutía le correspondió un cupo de ventas del 33,35 por 100 , y a la fábrica de Ziurrena, un 9,98 por 100 (Portland, Actas, ss. 30-11-1927). La cita ha sido tomada de Portland, $J G$, ss. 24-1-1928.

Q Véase Velarde (1973), pp. 149-150. 
defendió la creación de un Sindicato Nacional del Cemento que actuase como central de ventas, comprando cuanto se produjera, gozando del monopolio de la venta en España, encargado de fijar los cupos de producción de cada establecimiento y disfrutando de un derecho preferente para la instalación de nuevas plantas. Este proyecto, cuya autoría correspondía en parte a Portland, fue suscrito por el 75 por 100 de la producción nacional, lo que, de acuerdo con los porcentajes del cuadro 1, equivalía a la totalidad de las fábricas grandes. Un segundo proyecto propugnaba una libertad de precios dentro de unos límites, fijándose un sistema de compensaciones entre vendedores. En un primer momento, el Gobierno pareció decantarse por la propuesta de las grandes fábricas, pero acabó rechazándola para crear en su lugar una Comisión Asesora con carácter de Junta Reguladora e Inspectores de la Industria del Cemento (R. D. 5-1-1929). Constituían la Comisión once personas, de las cuales cinco figuraban como representantes de la Administración, tres como representantes de los constructores y los tres restantes de los cementeros ${ }^{91}$.

La intromisión del Estado en los asuntos internos del cártel fue aceptada por las grandes fábricas, quienes se referían a ella como algo habitual en un gran consumidor "que desea asegurarse las grandes cantidades de cemento necesarias a sus obras en cantidad, calidad y precio». Hubo fabricante que no dudó en calificarla como «muy acertada», pues defendía al consumidor cuyos intereses podían verse lesionados por elevaciones de precios. La intervención era, además, una garantía para el futuro, para «cuando declinen los accidentales grandes consumos». Estas citas denotan que los grandes cementeros vieron con satisfacción la intervención pública porque esperaban incrementar sus ventas a través de los contratos públicos. Por su parte, el Estado no tuvo inconveniente en ceder a las fábricas la exclusiva para el suministro de cemento, la exclusiva para obras de ampliación o instalación de nuevas plantas y la comercialización de las $220.000 \mathrm{Tm}$. importadas, lo que, sin duda, constituyó una operación lucrativa ${ }^{92}$.

¿Hasta qué punto se perpetuó con el paso del tiempo la buena disposición demostrada por las grandes fábricas? Hubo aspectos de la política económica de la Dictadura que dañaron los intereses de los fabricantes de portland. La obsesión demostrada por la Comisión Asesora por establecer un equilibrio entre producción y consumo favoreció la creación de nuevas fábricas, por lo general de pequeña escala. Al frenar la caída de los precios, la política estatal alargó la vida a las pequeñas fábricas ya existentes, que de no haber sido así

"Las fábricas habían propuesto cuatro nombres, siendo desestimado el cuarto por el Ministerio, de tal forma que los vocales en representación de los cementeros fueron Ferrer y Vidal, por Asland; Urriza, por Portland, y. Rojas Marcos, por la Sociedad Andaluza de Cementos Portland.

92 Portland, JG, ss. 26-1-1929. 
hubieran acabado por desaparecer. Las fábricas menos productivas intentaron valerse de los cárteles regionales para forzar una elevación de los precios. Cementos Portland se opuso siempre a estas elevaciones, que consideraba como los principales causantes de la entrada de nuevos competidores en el sector ${ }^{93}$. En el segundo semestre de 1929, Portland volvió a defender la oportunidad de proceder a una rebaja de los precios, quizá por detectar una mayor resistencia de los consumidores, planteando de forma abierta por vez primera la conveniencia de disolver el cártel del mercado norte ${ }^{94}$. Con su actitud, Portland dejaba el camino libre para un progresivo distanciamiento con respecto a la estructura oligopolista creada en 1926 al amparo de la política de la Dictadura.

\section{b) La crisis de 1930}

Las grandes fábricas revisaron sus expectativas sobre la evolución del sector cementero a comienzos de 1930: «... los grandes planes de Fomento y los generales de las Diputaciones y Ayuntamientos desataron las ambiciones de propios y extraños lloviendo sobre la Junta Reguladora peticiones de ampliación y de nuevas fábricas. Muchas fueron desestimadas, pero, desgraciadamente, se concedieron otras ... la nueva orientación del Gobierno, francamente restrictiva en cuanto a obras empezadas y proyectadas, causará para mediados de este año un desequilibrio bastante considerable entre producción y consumo. Esta es la verdad .... [nuestra ventajosa situación] nos permitirá hacer frente airosamente a la situación un tanto delicada del negocio en un futuro próximo...» ${ }^{95}$.

El empeoramiento de las expectativas de los fabricantes coincidió con el abandono de la política de obras públicas ${ }^{9}$. Este giro en la política económica generó inmediatas tensiones en el seno de los distintos cárteles regionales. Así, por ejemplo, en el momento en que se planteó prorrogar la Unión de Fabricantes del Litoral por un año más, Portland condicionó su aceptación a una rebaja de 25 pesetas en la tonelada de cemento y, en caso de que su propuesta no prosperase, declarar a Aragón como zona con libertad de precios. Al ser rechazadas ambas mociones por las restantes fábricas asociadas, Portland abandonó dicha Unión ${ }^{97}$. Por su lado, Asland, Auxiliar y Cementos Portland de Zaragoza reconocieron a Cementos Portland de Pamplona su derecho a co-

\footnotetext{
${ }^{93}$ Portland, Actas, ss. 30-3-1929.

Portland, Actas, ss. 27-9-1929.

95 Portland, $J G$, ss. 27-1-1930.

* Sobre las consecuencias del giro en la política de obras públicas para otros sectores, véase Cabrera (1983), pp. 83 et passim.

" Portland, Actas, ss. 7-3-1930.
} 
locar en el mercado de Aragón el mismo volumen de ventas que en 1929. Para alcanzar ese acuerdo tras intensas discusiones, Portland hubo de advertir a los demás fabricantes que su «necesidad de vender llegará hasta gestionar el servicio de nuestro cemento con una baja aproximada de 9 pesetas por tonelada.... ${ }^{98}$. Mientras que esto sucedía en los cárteles regionales, en la Unión nacional se establecieron cupos de ventas para cada fábrica ${ }^{99}$.

A partir de este momento se intensificaron las escaramuzas entre fábricas con recortes secretos de precios, en contra de lo estipulado por los cárteles que aún no habían sido denunciados. Por ejemplo, considérese este episodio entre las fábricas de Pamplona y Zaragoza: «ante la presión constante que Portland Zaragoza viene haciendo con nuestros clientes de Pamplona, se acuerda rebajar en 4 ptas/Tm. y advertir a aquella sociedad que sin más aviso bajaremos en 10 ptas. en Aragón en cuanto conozcamos una nueva gestión perturbadora por su parte» ${ }^{100}$. En Cataluña, los precios se mantuvieron estables en el primer semestre. A fines de junio, el conflicto se desencadenó al recortar los precios la casa Fradera después de haber incrementado su capacidad productiva. La respuesta de Asland no se hizo esperar: «... sin perjuicio de procurar unas bases de unión con la casa Fradera, se faculta a nuestros representantes... para que realicen las rebajas que sean necesarias sin limitación ni dilación alguna, presentando cuanto antes la batalla, procurando que la casa Landfort [Fradera] no se entere de los acuerdos de rebaja» ${ }^{101}$.

A tenor de los acontecimientos suscitados por el giro en la política económica, cabían varias opciones a las fábricas de cemento. La guerra de precios era, sin duda, la estrategia más efectiva. La capacidad de maniobra de los principales fabricantes era considerable tras los elevados niveles de beneficios conseguidos en la segunda mitad de la década de 1920. Rebajas de 5 o incluso 10 pesetas en el precio de la tonelada de cemento sólo representaban entre un tercio y un sexto de los beneficios unitarios de Portland en 1929. La segunda estrategia consistía en establecer nuevos pactos entre fabricantes con la esperanza de que fueran respetados por los firmantes y en tal caso llevar a cabo recortes secretos de los precios. Además, cuando los pactos establecían una compensación de 5 pesetas por tonelada de cemento vendida en exceso del cupo, los grandes fabricantes tenían un incentivo para traspasar ampliamente su cuota y realizar las economías de escala: compárese el cupo de

Ibidem, ss. 12-4-1930, 24-4-1930, 17-5-1930, 1-6-1930, 19-6-1930.

* A Portland le fue asignado un cupo de $125.000 \mathrm{Tm}$., debiendo abonar una compensación de 15 pesetas por cada tonelada métrica vendida en exceso (Portland, Actas, ss. 223-1930).

100 Ibidem, ss. 9-9-1930. También se recortaron los precios en el mercado de León con vistas a frenar la competencia de la sociedad Tudela Veguín (ibidem, ss. 30-10-1930).

${ }_{101}$ Asland, Actas, ss. 28-6-1930. 
125.000 toneladas asignado a Portland con un volumen de ventas de 167.000 toneladas. Una tercera opción era canalizar el cemento sobrante hacia el mercado exterior ${ }^{102}$.

$\mathrm{La}$ intensificación de la lucha competitiva entre fabricantes quedó plasmada en una disminución de los precios del cemento. Para la empresa Portland los beneficios medios disminuyeron en menor grado, lo que se explica por una reducción acorde de los costes medios gracias a la política de mecanización realizada por esta empresa ${ }^{103}$.

c) Tras una solución definitiva: la constitución de la COMAC, 1931-1935

La caída de los precios en 1930 sirvió de revulsivo a los fabricantes, quienes intensificaron sus gestiones para coaligar de forma definitiva a todas las fábricas. Las perspectivas empresariales para el año en ciernes eran, además, inciertas, «... siguiéndose en este primer mes el mismo rumbo...» ${ }^{104}$. Por esas razones, aparentemente no hubo dificultades para que el sector aceptara el proyecto de asociación presentado por Cementos Portland «como medio de evitar la ruinosa competencia que desde hace varios meses venimos haciéndonos». Los cupos de cada fábrica eran fijados de acuerdo con las ventas medias en el mercado interior, en los años 1929 y 1930, y con la capacidad instalada, que era aforada por una comisión de técnicos extranjeros para mayor imparcialidad. Los fabricantes debían de comprometerse a no realizar ampliaciones de capacidad y a no sobrepasar los cupos. Si las ventas eran excesivas, el fabricante pagaría una multa de 25 ptas/Tm. como compensación a las fábricas que vendieran menos. Toda la administración e inspección de las fábricas eran gestionadas a través de una oficina central. Sin embargo, el aspecto más innovador del proyecto era la libertad absoluta de precios ${ }^{105}$.

Para muchos, este proyecto era la solución definitiva para equilibrar oferta y demanda en el mercado español. La negativa de Fradera a integrarse en la nueva Unión si no se buscaba antes una solución al problema regional suscitado por ella misma dio al traste con todas las esperanzas ${ }^{106}$. La solución definitiva volvía a pasar por las manos de Fradera y de la Central de Ventas de Cataluña.

Fradera no era el principal fabricante catalán. En 1930, su participación en el total regional ascendió a un 26,6 por 100 , por detrás de Asland con un 53 por 100 . Aventajaba a la Auxiliar $(18,8$ por 100$)$ y, desde luego, a la re-

\footnotetext{
${ }^{102}$ Asland gestionó con el recién constituido Banco Exterior la comercialización de su cemento en el mercado argentino (Asland, Actas, ss. 6-10-1930).

${ }^{103}$ Gómez Mendoza (1986a).

104 Portland, JG, ss. 27-1-1931.

tos Portland, Actas, ss. 16-2-1931; Asland, Actas, ss. 16-2-1931.

${ }^{106}$ Asland, Actas, ss. 29-3-1931.
} 
convertida Frẹixa ( 3 por 100). La participación en las ventas dentro de la provincia de Barcelona tenía un orden de magnitud similar. Si nos atenemos a la capacidad de producción de cada fábrica, sería lógico pensar que el poder negociador de Fradera era menor que el de Asland y similar al de la Auxiliar. Pero la ventaja real de Fradera radicaba en su muy superior productividad, tres veces más alta que la de la fábrica de Moncada, perteneciente a Asland, y 2,6 veces más que la de la Auxiliar. Tan elevada productividad respondía a la calidad de las menas que beneficiaba y, sobre todo, a una mayor dotación de potencia instalada por obrero ${ }^{107}$. Ese nivel de productividad convertía a Fradera en el fabricante español de portland con la mejor estructura de costes, lo que, sin duda, le concedía amplio margen de maniobra en las reuniones del cartel. No hay que olvidar, además, que Fradera y Freixa se dedicaban también a la producción de cementos naturales. Esa diversificación de productos les permitía compensar las posibles pérdidas en un ramo con los beneficios del otro.

En espera de la resolución del contencioso con la casa Fradera, los principales fabricantes de portland gestionaron la canalización de los excedentes nacionales hacia el mercado exterior. La idea era colocar volúmenes crecientes de cemento en las Canarias, Marruecos, Guinea, América y en las colonias francesas e italianas. Con el apoyo de los ministros de Economía y Obras Públicas se creó una sociedad distribuidora del cemento en Canarias y Marruecos, que a tal efecto fijaba cupos de exportación ${ }^{108}$.

Al tiempo que se aseguraba esta salida para los excedentes interiores, una comisión de fabricantes establecía las bases para un nuevo cártel. Los cupos de ventas serían determinados tomando como base las capacidades declaradas por cada fábrica y las aforadas por la comisión técnica ${ }^{109}$. El pacto fue un éxito. Los beneficios medios de Cementos Portland superaron los niveles de 1929, compensando ampliamente la caída de $1930^{110}$.

En 1932, las expectativas empresariales volvieron a ser sombrías. La Unión no pudo evitar una nueva reducción de 61.000 toneladas en la cifra de ventas en el mercado nacional, lo que, sin embargo, constituía una imperceptible baja respecto al año anterior. A la debilidad de la demanda vino a sumarse una

${ }^{107}$ Los resultados anteriores pueden estar sesgados al alza por el hecho de que la capacidad instalada por Fradera era compartida por las dos secciones de la fábrica.

${ }^{108}$ Portland, Actas, ss. 9-5-1931; Asland, Actas, ss. 29-4-1931, 11-7-1932, 27-12-1932, 31-1-1933.

${ }_{109}$ Cuando la capacidad aforada excedía a la declarada, el cupo asignado era la semisuma de ambas. En caso contrario, se optaba por la capacidad declarada (Portland, Actas, ss. $26-5-1931,23-12-1931$ ).

${ }_{110}$ «Sin menoscabo de la libertad individual [el pacto] ha hecho desaparecer la fuerte competencia de $1930 \ldots$ el acuerdo establecido ha servido para mantener íntegra nuestra serenidad y nuestra moral» (Portland, $J G$, ss. 14-1-1932). 
nueva muestra de lo que los fabricantes consideraban intromisión gubernamental. A comienzos de año, el Ministerio de Obras Públicas creó una Junta Asesora de la Industria del Cemento, cuyo objeto era combatir los beneficios excesivos del sector. Perseguía esta Junta que los precios se fijaran según los verdaderos costes marginales: «... como en ella [la Junta] están representados los consumidores y defienden con enorme tesón la necesidad y la justicia, interpretados a su modo, de bajar los precios, inútil es deciros de que, a pesar de que también la representación de las fábricas trabaja con interés para demostrar lo absurdo y peligroso de una baja impuesta oficialmente en estos momentos, tenemos sobre nuestras cabezas la amenaza de alguna disposición oficial... Abrigamos la esperanza, sin embargo, de que al fin prevalecerá nuestro criterio como fundado en razones y datos incontrovertibles» ${ }^{111}$.

Para Cementos Portland, 1932 fue un año relativamente satisfactorio, pues a fuerza de vender a precios por debajo de los generales consiguió realizar economías de escala y minimizar de este modo la caída de los beneficios medios (véase gráfico 2). El caso de Portland pudo ser excepcional. Cementos Freixa experimentó una baja en sus beneficios durante el primer semestre en comparación con igual período del año anterior, lo que la sociedad atribuía al efecto combinado de la recesión en las ventas y un aumento de los costes por disminución de la productividad ${ }^{112}$.

La insatisfacción por los resultados del año motivó entre los fabricantes de portland críticas hacia el pacto recién establecido en 1931. Su principal defecto era el no contemplar posibles rebajas de los precios: «un fabricante que no alcance su cupo puede impunemente deshacer un mercado» ${ }^{113}$. En julio de 1933 se estableció un nuevo pacto, hasta finales de año, que no contenía novedades significativas, por lo que debía interpretarse como una mera fórmula de continuidad ${ }^{114}$.

Al cerrar el ejercicio de 1933 la situación había empeorado sustancialmen. te: las ventas de cemento portland se habían reducido en 136.000 toneladas, lo que significaba una aceleración respecto al período anterior. Los beneficios medios realizados por Cementos Portland descendieron por segundo año consecutivo, mientras que la sociedad Freixa escapaba a los números rojos gracias a las compensaciones hechas efectivas por la Unión. En esas condiciones, los

111 Ibidem, ss. 14-1-1933.

112 Freixa, Actas, ss. 6-7-1932.

113 Portland, Actas, ss. 11-2-1933.

114 El cupo asignado a Portland representaba un 10,67 por 100 del mercado. Además, se establecían 25 pesetas como compensación cuando las ventas excedieran del cupo y se permitía la libertad de precios. En cambio, desaparecía la indemnización por paralizar parte de la capacidad productiva. El nuevo pacto era considerado por el Consejo de Portland como una tregua hasta que se clarificase el mercado (Portland, Actas, ss. 112-1933). 
fabricantes estaban convencidos de que los pactos de 1931 y 1933 no eran la solución ante la persistencia en la recesión de la demanda de consumo. Los antagonismos entre fábricas volvieron a aflorar. Insatisfecha por el cupo que le había sido asignado, Cementos Portlland reclamó ante la Unión que la recién estrenada fábrica de Mataporquera fuera paralizada por dos años. Al ser desoída su proposición, Portland abandonó la Unión porque era «...preferible dar de lado a la Unión, que a otros favorece, y obrar en adelante con la máxima libertad y seguir como nos lo aconsejen las circunstancias»" ${ }^{115}$.

Como ocurrió en otras ocasiones, su decisión no fue duradera. La caída sostenida en las ventas; la tendencia a la baja de los precios, que era calificada como «ruinosa»; la amenaza de una nueva intervención oficial en la industria, «de la que deben huir las sociedades», y la «tan incierta situación económica y política» fueron motivos más que suficientes para entablar nuevas discusiones en torno a la constitución de un nuevo cártel.

Una primera opción consistió en la formación de centrales regionales de ventas cuya misión era establecer cupos fijos a un nivel de precios basado en los precios medios obtenidos por cada fábrica en los dos años anteriores. Desaveniencias entre los fabricantes hicieron fracasar el proyecto ${ }^{116}$. El peligro de que se acentuara la competencia en aquel momento tan poco propicio para los intereses de las industrias fue el catalizador que impulsó la aceptación de la segunda opción. Consistía ésta en establecer una sociedad anónima que actuase como central de ventas para el conjunto del territorio nacional. De este modo, en mayo de 1934, nació la sociedad Comercial de Materiales de Construcción (COMAC) ${ }^{117}$.

Al constituirse la COMAC se cancelaron todos los pactos anteriores. Esta sociedad actuaba como un monopsonista adquiriendo toda la producción de cada fábrica por espacio de cuatro años. Tenía la exclusividad de venta en la Península a los precios que creía conveniente fijar, pagando un precio único a pie de fábrica. Los servicios comerciales quedaban organizados en cada región por medio de agencias de ventas, que podian a veces coincidir con los fabricantes. COMAC concedió a Cementos Portland un cupo del 11,424 por 100 sobre la cifra de ventas totales (estimadas en 1,35 millones de toneladas), a un precio en fábrica de 70,42 pesetas por tonelada ${ }^{118}$.

"Ibidem, ss. 22-12-1933.

116 Ibidem, ss. 23-2-1934; JG, ss. 15-1-1934; Asland, Actas, ss. 7-3-1934, 7-4-1934.

117 El capital de la nueva sociedad fue suscrito en participaciones, que desconozco, por las grandes fábricas cementeras (Portland, Actas, ss. 21-5-1934; Asland, Actas, ss. 18-51934, y Freixa, Actas, ss. 21-6-1934). Para Freixa, la constitución de COMAC significó la posibilidad de continuar la fabricación, pues en los días anteriores la sociedad había iniciado los trámites para el cierre de sus instalaciones.

"il Este precio era sobre vagón y sin envase, revisable trimestralmente (Portland, $A c$ tas, ss. 1-7-1934). 
Sería conveniente conocer los acuerdos establecidos con las otras sociedades y evaluar sus efectos sobre la industria del portland. A primera vista, COMAC era una solución ideal: compraba toda la producción a un precio fijo, por lo que los fabricantes podían despreocuparse de la comercialización. $\mathrm{Si}$ nos atenemos a los resultados de Cementos Portland, puede afirmarse que COMAC resultó beneficiosa en extremo. En efecto, los beneficios medios de Portland aumentaron en 1934 por vez primera en tres años (véase gráfico 2). Los precios se estabilizaron e incluso comenzaron a subir. Las ventas siguieron deprimidas, aunque a finales de año Cementos Freixa experimentó síntomas de una ligera mejoría. En cualquier caso, la evolución de las ventas no interesaba de forma directa a los fabricantes. Sí les preocupaba, en cambio, el hecho de que todo el andamiaje amenazaba con derrumbarse de nuevo por la intransigencia de ciertas fábricas, entre ellas Fradera, a aceptar los acuerdos de 1934. En octubre de 1935, Fradera optó por rescindir su acuerdo con la central de ventas: «Creemos firmemente al tomar esta decisión defender la industria del cemento portland artificial, acabando por nuestra parte con la situación actual que $\tan$ gravemente la perjudica» ${ }^{119}$.

La separación fue corta. En noviembre, Fradera y COMAC llegaron a un principio de acuerdo, consumándose la reincorporación definitiva a comienzos de $1936^{120}$. Los acontecimientos posteriores nos impiden saber si la central de ventas fue capaz de dar solución al problema de la sobreproducción. Sí está claro, en cambio, que para los fabricantes de cemento artificial la actuación de la $C O M A C$ fue excelente. En efecto, se alcanzó un nivel récord de beneficios medios, que superó en 6 pesetas por tonelada el máximo de 1919 y que sobrepasó ampliamente los beneficios logrados durante los tres últimos años del Directorio militar. El hecho es tanto más significativo por cuanto en 1935 el consumo de cemento artificial había caído un 30 por 100 por debajo de los niveles de 1929.

\section{ALGUNAS CONSIDERACIONES FINALES: OLIGOPOLIO, PRECIOS Y EFICIENCIA}

A los pocos años de su nacimiento, la industria del cemento artificial presentaba un cuadro clínico más propio de un sector en declive secular que de una industria nueva. Sus síntomas eran parecidos a los que presentaban en el mercado de entreguerras industrias «enfermas» típicas como la hullera, la textil algodonera o los ferrocarriles en Inglaterra. Para la industria española del ce-

119 Cementos Fradera, Actas, ss. 12-8-1935.

120 Ibidem, ss. 7-11-1935, 11-1-1936. 
mento portland el síntoma más grave era una tendencia crónica al exceso de capacidad, que en 1935 era cercano a un 60 por 100, y rigideces estructurales que impedían una reasignación de recursos hacia otros sectores más boyantes.

Durante el primer tercio del siglo $\mathrm{xx}$, la industria del cemento artificial atravesó por dos fases de crisis: 1922-1926 y 1930-1934. En ambas ocasiones coincidieron una recesión cíclica de la economía internacional con una demanda deprimida en el mercado interior como continuación a periodos de intensa demanda.

En ambos casos, la salida a la crisis pudo haberse realizado por cauces muy distintos a los reales. El mercado habría podido convertirse en una eficaz arma: el exceso de capacidad habría deprimido los precios interiores restando rentabilidad a las empresas menos eficientes, obligándolas. a abandonar el sector. El proceso habría continuado hasta alcanzarse un nuevo equilibrio entre oferta y demanda de cemento.

Nada de esto ocurrió. Lejos de cerrarse fábricas, el número de establecimientos dedicados a la fabricación de portland se incrementó en 22 , al tiempo que la capacidad instalada se quintuplicó entre 1919 y 1934. La explicación a tan sorprendente comportamiento está en el gráfico 2: incluso en los años difíciles, la industria fue rentable. En efecto, tomando como indicador los beneficios medios logrados por la segunda mayor sociedad del sector, observamos que éstos fueron excepcionalmente altos incluso cuando se hablaba de crisis, lo que lejos de ahuyentar a los inversores, antes bien, atrajo nuevos capitales.

¿Por qué entonces fueron tan altos los beneficios medios durante el primer tercio del siglo $\mathrm{xx}$ en la industria del cemento artificial? En gran parte, y ésta es la respuesta dada en las páginas anteriores, se debió a la estructura oligopolista del sector. En menor parte se debió a la buena gestión de las empresas, es decir, a su capacidad para recortar sus costes medios realizando economías de escala, mecanizando la fabricación, mejorando el aprovisionamiento en materias primas y los canales de distribución del producto final. De todo ello existen amplias evidencias que han sido analizadas en otro lugar ${ }^{121}$.

En la medida en que los precios, más elevados que los competitivos, ayudaron a sobrevivir a toda una serie de fabricantes poco eficientes, puede afirmarse entonces que la existencia del oligopolio del cemento agravó la situación, retrasando en el tiempo su desenlace. De haber sido abandonadas a las fuerzas del mercado, esas fábricas habrían sido las primeras en desaparecer. En este sentido, el oligopolio habría provocado una mala asignación de recursos.

Hemos tenido ocasión de ver que el oligopolio del portland no nació a

${ }^{121}$ Gómez Mendoza (1986a). 
consecuencia de una crisis. En la misma naturaleza de esa industria va inherente su carácter oligopolista. De ahí que el cártel del cemento fuera una creación temprana, casi tanto como la propia industria.

Volviendo a la cuestión de la capacidad, ¿cuáles fueron las razones para que ésta aumentara? En tiempos de bonanza la capacidad se expandía por la llegada de nuevas fábricas, lo que, a su vez, dependía de lo importantes que fueran las barreras de entrada en el sector, y por los aumentos de capacidad entre las fábricas ya establecidas. Hemos detectado que a partir de 1919 fue relativamente más fácil acceder a este sector. En definitiva, la efectividad de las barreras de entrada dependía de la rentabilidad de la industria. Las fábricas ya existentes tenían, además, otros motivos para ampliar su capacidad: alcanzar la escala óptima de fabricación, aprovechar los pactos entre fabricantes que asignaban generalmente cupos de ventas atendiendo a la capacidad instalada.

Repasando la evolución del sector cementero en el período considerado se aprecia una repetición de la misma secuencia de acontecimientos:

Pacto $\rightarrow$ Estabilización/aumento de los precios $\rightarrow$ Aumentos de los beneficios $\rightarrow$ Entrada de nuevas fábricas $\rightarrow$ Denuncia del pacto $\rightarrow$ Guerra de precios $\rightarrow$ Caída de los beneficios $\rightarrow$ Nuevo pacto...

El análisis anterior ha puesto de manifiesto la existencia de una relación entre la eficacia del oligopolio, es decir, su capacidad para mantener elevado el nivel de beneficios, y factores tales como la concentración industrial y el control del mercado. Cuando el número de fabricantes era pequeño, como fue el caso entre 1906 y 1919, los beneficios se conservaron elevados, aunque no lo suficiente para evitar una pérdida en términos reales. Por el contrario, a medida que aumentaba el número de fabricantes perdía operatividad el cártel, como lo prueba el hecho de que en 1927-1929, a pesar de coincidir con unas condiciones excepcionalmente favorables, el aumento de los beneficios fuera modesto. En cambio, la $C O M A C$, que funcionaba prácticamente como un monopolista desde el momento en que vinculó a todos los fabricantes españoles, permitió alcanzar unos beneficios máximos a pesar de coincidir con una recesión profunda en la demanda de consumo.

Las comparaciones entre el nivel de beneficios en uno y otro período se ven realzadas al expresar los beneficios en relación con los precios del portland. Mientras que en relación con el índice general de precios al consumidor los beneficios de 1935 exceden en un 9,2 por 100 a los de 1919 , su ventaja aumenta hasta un 48 por 100 si los relacionamos con los precios del cemento ${ }^{122}$.

${ }^{122} \mathrm{El}$ precio convenido entre Cementos Portland y la COMAC era 70 ptas/Tm. sobre vagón y sin envase. Por el contrario, el precio de 1919 incluye el envase. En ese año, 
Un último aspecto a destacar es el relativo a los precios del portland. ¿En qué medida fueron capaces los sucesivos cárteles de controlar las fluctuantes de los precios? Una respuesta a esta pregunta requiere el contar con series de precios anuales en los distintos mercados (y preferiblemente para una misma marca). En el estado actual de la investigación no contamos aún con esas series, lo que nos obliga a basar nuestro análisis en los mecanismos por los cuales se fijaban los precios del cemento. Era costumbre entre los fabricantes aplicar precios distintos discriminando en razón de la localización geográfica del cliente, y a veces en razón del propio cliente. Uno y otro tipo de discriminación cuentan con numerosos ejemplos que han sido analizados en otro lugar ${ }^{123}$. Me limitaré aquí a exponer cuáles fueron los efectos económicos de la discriminación de precios.

Por la propia naturaleza de la industria, los precios del portland fluctuaron en el primer tercio del siglo $\mathbf{x x}$ entre los límites marcados por la competencia y el monopolio. Según las épocas, el precio medio del portland se acercó a uno u otro extremo. En concreto, cuando se acentuaba la competencia, como ocurrió entre 1922 y 1926, el nivel de precios disminuyó en beneficio de los consumidores de portland. Por otro lado, es evidente que el mero establecimiento de pactos entre fabricantes, en la medida en que incitaba a algunos a violar los acuerdos con ánimo de captar clientes, era de por sí una garantía de que el precio efectivo nunca alcanzó el nivel del equilibrio monopolista. Sin embargo, una estructura perfectamente competitiva tampoco habría beneficiado al consumidor, pues la libertad de entrada en el sector habría permitido el establecimiento de un número muy superior de fábricas con escasa capacidad y con una estructura de costes que les habría impedido vender a precios bajos.

Los efectos de la discriminación de precios sobre la asignación de recursos están poco claros. Se dio el caso de empresas como Portland que deliberadamente vendían menos en los mercados menos rentables, que solían ser aquellos como Madrid en los que competía el cemento de varias marcas. Solía tratarse de mercados caracterizados por una elevada elasticidad-precio de la demanda, por lo que cualquier recorte en los precios, fruto de una guerra de precios, se habría traducido necesariamente en un aumento más que proporcional del consumo. Otro efecto de la discriminación fue ejercer una redistribución de la

Portland adquirió sacos de yute al precio de 1,04 pesetas la unidad. Como se requerían 20 sacos para envasar una tonelada de cemento, resulta un precio de 119,2 ptas/Tm. sin envase (Portland, Actas, ss. 15-7-1919).

${ }^{123}$ Gómez Mendoza (1987). 
renta a favor de las regiones donde el cemento se vendía más barato. Por consiguiente, hubo transferencias de renta a favor de mercados como Barcelona o Madrid en detrimento de provincias como Navarra, Oviedo o Valencia, que tan sólo contaban con una fábrica de portland.

\section{BIBLIOGRAFIA}

Cabrera, M. (1983): La Patronal ante la II República. Organizaciones y Estrategia, 1931-36, Madrid, Siglo XXI.

Davis, A. C. (1909): Portland Cement, Londres.

FoG, B. (1956): «How are cartel prices determined?», Journal of Industrial Economics, $\mathrm{V}, 1$.

Gómez Mendoza, A. (1986): «La Industria de la Construcción Residencial: Madrid 18201935 , Moneda y Crédito, 177, pp. 53-81.

- (1986 a): «Oligopolio y Eficiencia Económica: La Industria del Cemento Portland, 1899-1935», ponencia presentada en el II Seminario de Historia Económica Cuantitativa, Madrid.

- (1987): «El Oligopolio del Cemento Portland, 1906-36: Barreras de Entrada, Productividad y Discriminación de Precios» (inédito).

LOESCHER, S. (1959): Imperfect Collusion in the Cement Industry, Cambridge.

Machlup, F. (1955): "Characteristics and Types of Price Discrimination», en NBER: Business Concentration and Price Policy, Nueva York.

Meyzenc, R. (1968): Perspectives Energétiques de l'Industrie des Ciments, París.

De Miguel, A. (1935): El Potencial Económico de España, Madrid.

Ministerio de Fomento (1929): Comisión Asesora con Carácter de Junta Reguladora $e$ Inspectora de la Industria del Cemento, Madrid.

Palomar, P. (1940): La Industria Española del Cemento, Barcelona.

- (1941-42): «Actuación de los Ingenieros Industriales en la Dirección y Progreso de la Industria Española del Cementom, en Escuela Especial de Ingenieros Industriales: Lecciones sobre la Industria del Cemento, Madrid.

PIGOU, A. C. (1920): The Economics of Welfare, Londres.

SCh erer, F. M. (1970): Industrial Market Structure and Economic Performance, Chicago.

STIGLER, G. (1964): «A Theory of Oligopoly», Journal of Political Economy, 72, pp. 44-61.

U. S. Federal Trade Commission (1966): On Mergers and Vertical Integration in the Cement Industry, Washington.

Velarde Fuertes, J. (1973): Politica Económica de la Dictadura, Madrid. 